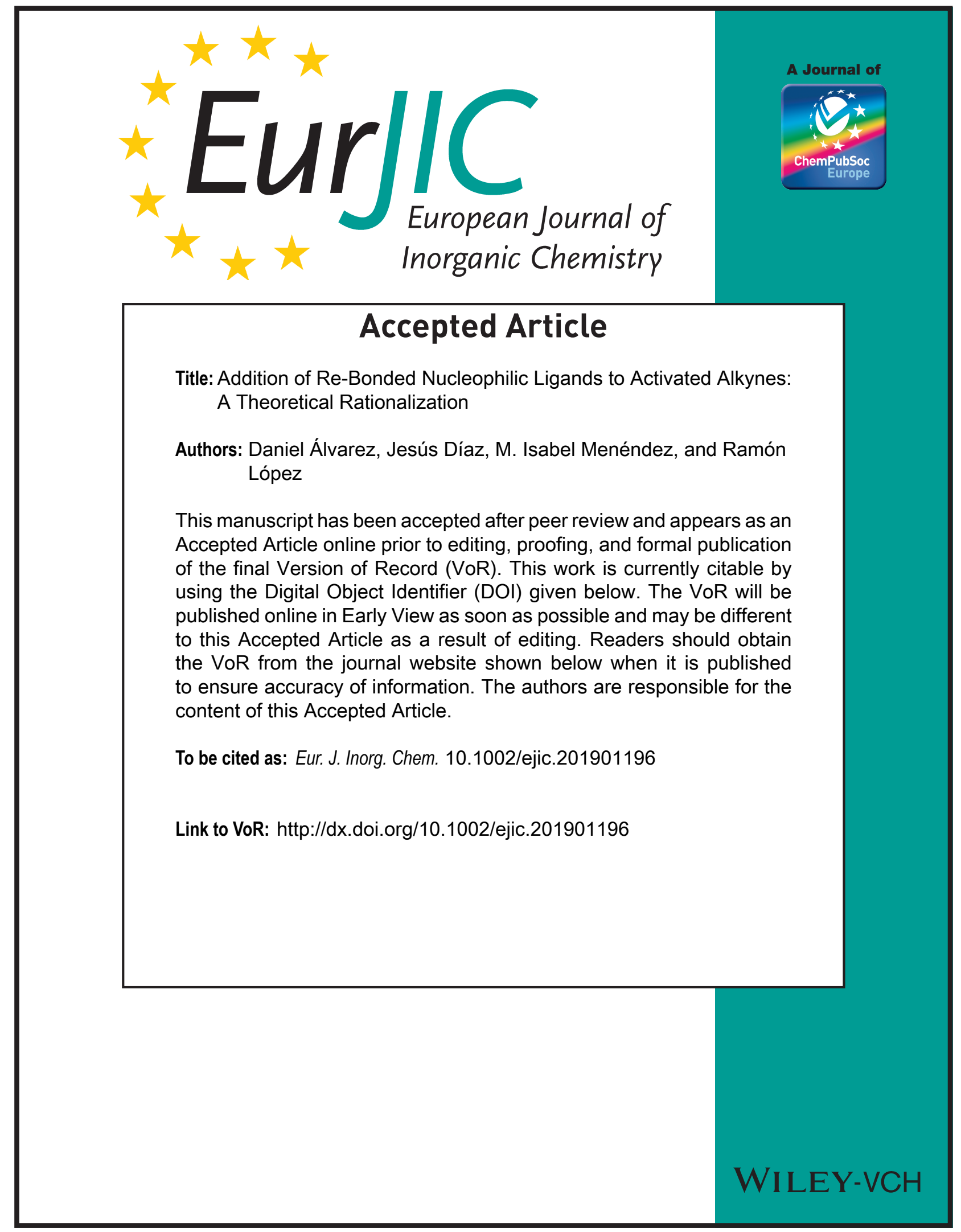




\section{Addition of Re-Bonded Nucleophilic Ligands to Activated Alkynes: A Theoretical Rationalization}

\begin{abstract}
Daniel Álvarez, ${ }^{[a]} J e s u ́ s ~ D i ́ a z,{ }^{[b]} M$. Isabel Menéndez,
Abstract: Reactions between $\left[\operatorname{Re}(\mathrm{X})(\mathrm{CO})_{3}(\mathrm{bipy})\right](\mathrm{X}=\mathrm{OH}$, OMe, $\mathrm{NH} p \mathrm{Tol}, \mathrm{PPh}_{2}$; bipy = 2,2'-bipyridine) complexes and methyl propiolate (HMAD) are studied to rationalize the different products experimentally obtained. Three reaction patterns were found with a common and limiting initial attack of $X$ to HMAD. Thus, the experimental selectivity depends on the kinetics and/or thermodynamics of the last reaction stages. For $\mathrm{X}=\mathrm{OH}$ and $\mathrm{NHpTol}$ an easy intramolecular attack of the X-linked HMAD to a highly electrophilic $\mathrm{CO}$ ligand is followed by a hydrogen transposition to this $\mathrm{CO}$, yielding very stable species ( $C-\mathrm{C}_{\mathrm{COH}}$ products). When $\mathrm{X}=\mathrm{OMe}$, the insertion of the X-attached HMAD into the Re-OMe bond (ins product) takes place due to the smallest barrier and the largest stability of the ins route. Finally, when $\mathrm{X}=\mathrm{PPh}_{2}$ the ins route becomes restricted and the route for the coupling of the $X$-attached HMAD with bipy $\left(C-C_{\text {bipy }}\right.$ product) wins over the one for the coupling with $\mathrm{CO}\left(C-C_{C O}\right.$ product) only due to the larger stability of the $C-C_{\text {bipy }}$ product.
\end{abstract}

\section{Introduction}

Rhenium(I) tricarbonyl complexes of the general formula fac$\left[\operatorname{Re}(\mathrm{CO})_{3}(\mathrm{~N}-\mathrm{N}) \mathrm{L}\right]^{n}$, where $\mathrm{N}-\mathrm{N}$ is a $2,2^{\prime}$-bipyridine or $1,10-$ phenanthroline-based diimine ligand and $L$ is neutral $(n=+1)$ or anionic $(n=0)$ monodentate ligand, are involved in numerous, diverse, and important applications. Among others, that kind of Re compounds has been investigated as photocatalysts and/or electrocatalysts for reducing $\mathrm{CO}_{2}$ and $\mathrm{H}^{+}\left(\mathbf{1 - 1 6}\right.$ in Scheme 1), ${ }^{[1-18]}$ molecular sensors or photoswitches (16-20 in Scheme 1), ${ }^{[19-26]}$ emitting centers in organic light-emitting diodes $(\mathbf{1}, \mathbf{1 1}, \mathbf{1 2}, \mathbf{1 7}$, 18, and 21-23 in Scheme 1), ${ }^{[2]}$ anticancer agents (15 and 24-34 in Scheme 1), ${ }^{[28-34]}$ cellular and biomolecular imaging agents (1, 2, and 35-39 in Scheme 1), ${ }^{[35-46]}$ or reagents for synthesizing new organometallic compounds $(3,4$, and $40-44$ in Scheme 1). ${ }^{[47-54]}$ These applications can be adjusted by choosing the diimine ligand $\mathrm{N}-\mathrm{N}$ or the monodentate ligand $\mathrm{L}$ with the appropriate substituents. Besides this, the changes in the noncarbonyl ligands of the $\operatorname{Re}(\mathrm{I})$ complexes can also drastically

[a] D. Álvarez, Dr. M. I. Menéndez, Dr. R. López Departamento de Química Física y Analítica Universidad de Oviedo

C/ Julián Clavería 8, 33006 Oviedo, Asturias, Spain E-mail: rlopez@uniovi.es

\section{[b] Dr. J. Díaz}

Departamento de Química Orgánica e Inorgánica Universidad de Extremadura

Avenida de la Universidad s/n, 110071 Cáceres, Extremadura, Spain

Supporting information for this article is given via a link at the end of the document.

\author{
${ }^{[a]}$ and Ramón López ${ }^{*[a]}$
}

modify their reactivity towards other molecular systems. Particularly, several experimental findings have shown that the reaction between the complexes $\left[\operatorname{Re}(\mathrm{X})(\mathrm{CO})_{3}(\mathrm{~N}-\mathrm{N})\right] \quad(\mathrm{X}=\mathrm{OH}$ (hydroxo), OMe (methoxo), NHpTol (para-tolylamido), $\mathrm{PPh}_{2}$ (diphenylphosphanido); N-N = 2,2'-bipyridine (bipy); 1,10phenanthroline (phen)) and activated alkynes like methyl propiolate (HMAD) or dimethylacetylenedicarboxylate (DMAD) gives rise to the formation of different reaction products. ${ }^{[47,49-52]}$ The product formed depends on the nucleophilic ligand $(X)$ used, rather than the bidentate ligand of the metal complex (see below). Molybdenum(II) complexes of type $\left[\mathrm{Mo}\left(\eta^{3}-\right.\right.$ allyl) $\left.(\mathrm{X})(\mathrm{CO})_{2}(\mathrm{~N}-\mathrm{N})\right](\mathrm{X}=\mathrm{OH}$, OMe, NHpTol; N-N = bipy, phen) have also shown the same reactivity patterns against activated alkynes as their $\operatorname{Re}(\mathrm{I})$ analogues. ${ }^{[47-52]}$
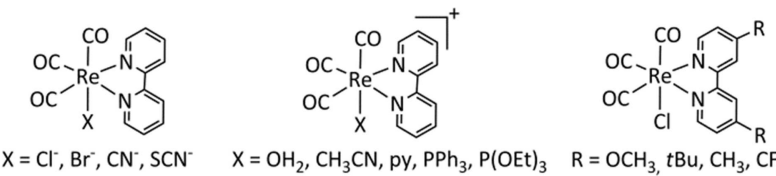

$$
\begin{array}{llll}
1 & 2 & 3 & 4
\end{array}
$$

$\mathrm{X}=\mathrm{OH}_{2}, \mathrm{CH}_{3} \mathrm{CN}$, py, $\mathrm{PPh}_{3}, \mathrm{P}(\mathrm{OEt})_{3} \quad \mathrm{R}=\mathrm{OCH}_{3}, \mathrm{tBu}, \mathrm{CH}_{3}, \mathrm{CF}_{3}, \mathrm{CN}$

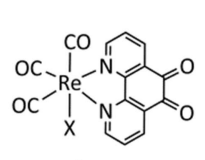

$\mathrm{X}=\mathrm{Cl}^{-}, \mathrm{Br}^{-}$ 1516

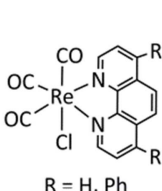

$\mathrm{R}=\mathrm{H}, \mathrm{Ph}$
1718

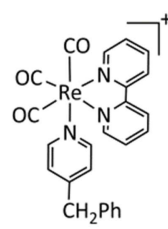

19

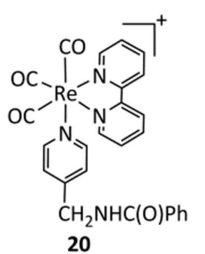

20
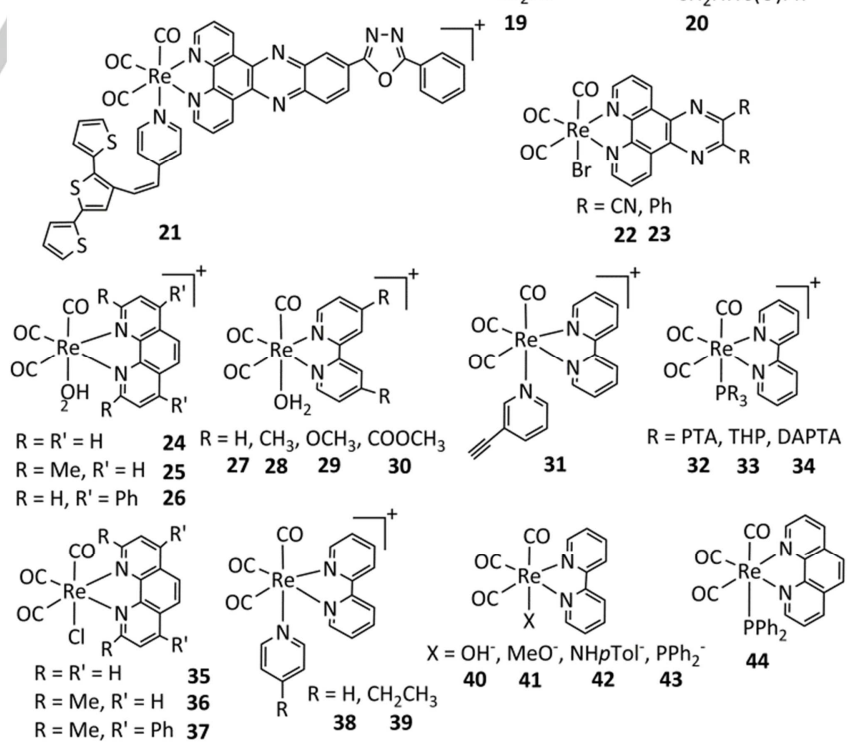

Scheme 1. Basic structures of rhenium(I) tricarbonyldiimine complexes containing neutral or anionic monodentante ligands involved in diverse applications. 
According to experimental findings, it has been suggested that all reactions between $\left[\operatorname{Re}(\mathrm{X})(\mathrm{CO})_{3}(\mathrm{~N}-\mathrm{N})\right]$ and activated alkynes start with an initial attack of the nucleophilic ligand $X$ to one of the acetylenic carbon atoms to form a zwitterionic intermediate (I in Scheme 2). ${ }^{[51,52]}$ In this scheme, $X$ was replaced by YR to better follow the formation of the different types of reaction products. In the amido and hydroxo complexes the just added alkyne binds to a CO ligand in cis disposition (see Pcco species in Scheme 2) and transposition of a proton from the nucleophilic ligand to the attacked $C O$ takes place $\left(C-C_{C O}\right.$ route and Pccoh product in Scheme 2). ${ }^{[49,50]}$ Alternatively, in the alkoxo complex the alkyne inserts into the Re-OMe bond (ins route and Pins product in Scheme 2). ${ }^{[47]}$ Finally, the phosphanido complex leads to the formation of a different kind of product coming from the addition of the alkyne to the bidentate ligand $\left(C-C_{b i p y}\right.$ route and $\mathrm{Pccb}$ product in Scheme 2) ${ }^{[51,52]}$ This last reaction is remarkable because of the inertness of coordinated bipy and phen. Furthermore, this result stands in contrast with the Pcco-type products reported for the reaction towards activated alkynes of $\mathrm{Fe}, \mathrm{Mo}, \mathrm{W}$, and $\mathrm{Ir}$ complexes containing the same $\mathrm{PPh}_{2}$ phosphanido ligand ${ }^{[55-57]}$ and with Pins-type product detected in case of a $\mathrm{Nb}$ complex. ${ }^{[58]}$ It is also believed that the reaction of a stannylphosphole complex with DMAD evolves through an intermediate resulting from the alkyne insertion into the P-Sn bond. ${ }^{[59]}$

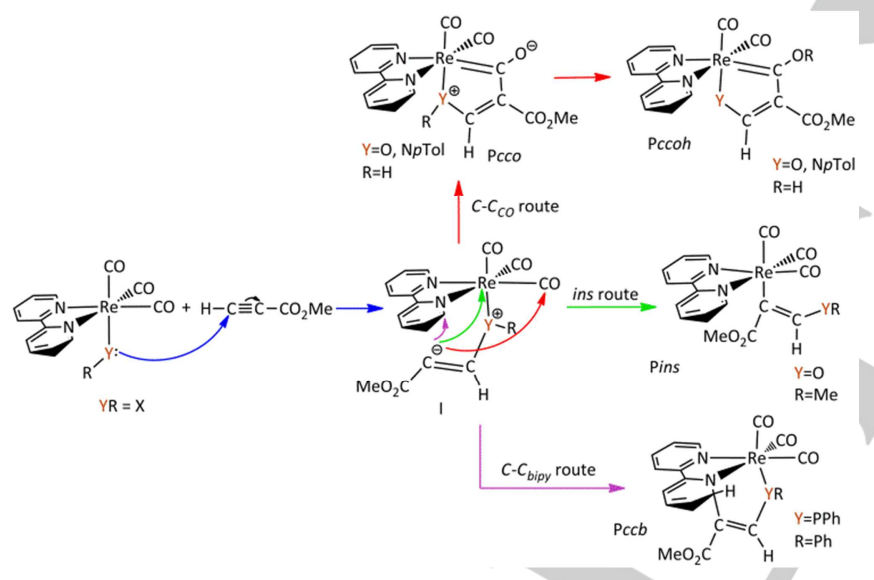

Scheme 2. Reaction mechanisms suggested for the reaction of rhenium(I) tricarbonyl complexes containing a nucleophilic ligand $(X)$ with methyl propiolate (HMAD). For clarity, the YR label for $X$ was used here.

Within this framework, we wondered about the aspects of the nucleophile ligand that are key to obtaining a given product in the reaction of $\operatorname{Re}(\mathrm{I})$ complexes and activated alkynes. This is particularly important to get a better understanding of such chemistry, but above all to gather information that could guide a strategy to tune those complexes in order to get new or improved technological, biomedical or chemical synthesis applications. For instance, a systematic modification of the axial ligands to a substituted bipy ligand has allowed for red-shifted absorbance features in $\operatorname{Re}(\mathrm{l})$ carbonyl complexes. ${ }^{[60]}$ Computations have been crucial to show that the aforementioned result is a consequence of destabilization of the Re $d$-orbitals. Therefore, we undertook a comparative theoretical study on the reactivity of $\left[\operatorname{Re}(\mathrm{X})(\mathrm{CO})_{3}\right.$ (bipy) $](\mathrm{X}=\mathrm{OH}, \mathrm{OMe}$, $\mathrm{NH} p \mathrm{Tol}, \mathrm{PPh}_{2}$ ) complexes and HMAD. The choice of the simplest bidentate ligand bipy and activated alkyne HMAD in this investigation does not imply a loss of generality of the results obtained, although there is indeed a significant improvement in the computational cost-efficiency ratio. The reactive process involving the $\mathrm{PPh}_{2}$ ligand had been previously investigated from a theoretical point of view. ${ }^{[61]}$ The reaction mechanism found is closely related to that shown in Scheme 2 (see below) and confirms the product experimentally found. However, the results of this single study are not enough to rationalize the formation of different products when $\mathrm{PPh}_{2}$ is replaced by $\mathrm{OH}, \mathrm{OMe}$ or $\mathrm{NH}$ Tol. The type of atom directly linked to $\operatorname{Re}(\mathrm{O}, \mathrm{N}$ or $\mathrm{P})$ and/or its substituents $\left(\mathrm{H}, \mathrm{Me}, \mathrm{HpTol}\right.$ or $\left.\mathrm{Ph}_{2}\right)$ seem to be responsible for the selectivity of the reaction and, consequently, the present research is needed to clarify their particular effects.

\section{Computational Chemistry Details}

Full geometry optimizations of the species involved in the reactive processes between $\left[\mathrm{Re}(\mathrm{X})(\mathrm{CO})_{3}(\mathrm{bipy})\right](\mathrm{X}=\mathrm{OH}$, OMe, $\mathrm{NH} p$ Tol) and HMAD were carried out in tetrahydrofuran (THF, $\varepsilon$ = 7.58) solution at the PCM-B3LYP/6-31G+(d,p) (LANL2DZ for $\mathrm{Re}$ ) level. The nature of the critical structures located on the different potential energy surfaces (PES) investigated was verified by means of harmonic vibrational frequency computations. Normal-mode analysis of the imaginary frequency in the transition states (TS) and intrinsic reaction coordinate (IRC) calculations with the second order Gonzalez-Schlegel integration method ${ }^{[62]}$ were carried out in order to connect each TS to the two associated minima of the proposed mechanism. To get more accurate energies (particularly energy barriers), single-point energy calculations on the PCM-B3LYP/6-31G+(d,p) (LANL2DZ for $\mathrm{Re}$ ) geometries were performed using the domain localized pair natural orbital-coupled cluster approach with single, double, and perturbative triple excitations (DLPNO-CCSD $(T)$ ). ${ }^{[63]}$ The balanced Karlsruhe triple-zeta basis set def2-TZVPP ${ }^{[64]}$ and the conductor-like polarizable continuum model $(\mathrm{CPCM})^{[65]}$ were used in the DLPNO-CCSD(T) computations. All organometallic systems investigated showed $\mathrm{T} 1$ diagnostic values less than $0.02,{ }^{[66]}$ suggesting that a multi-reference treatment is not necessary. In general, DLPNO-CCSD(T) energies are more accurate than B3LYP ones using at least a triple-zeta quality basis set. ${ }^{[67]}$ For comparison purposes, the single-point energy of the species containing the $\mathrm{PPh}_{2}$ ligand, previously investigated at the PCM-B3LYP/6-311+G(2d,p) (LANL2TZ+ $f$ for $\mathrm{Re}) / / \mathrm{PCM}-\mathrm{B} 3 \mathrm{LYP} / 6-31+\mathrm{G}(\mathrm{d}, \mathrm{p})$ (LANL2DZ for Re) level, ${ }^{[61]}$ was also recomputed at the CPCM-DLPNO-CCSD(T)/def2TZVPP//PCM-B3LYP/6-31+G(d,p) (LANL2DZ for Re) one (Tables S1-S4 in the Supporting Information). For brevity, henceforth in this work, the levels of theory PCM-B3LYP/6$31+G(d, p) \quad(L A N L 2 D Z$ for $R e$ ) and CPCM-DLPNO$\operatorname{CCSD}(T) /$ def2-TZVPP//PCM-B3LYP/6-31+G(d,p) (LANL2DZ for 
Re) will be denoted as B3LYP and DLPNO-CCSD(T), respectively.

Thermal free energy corrections in THF solution $\left(G_{\text {therm }}\right)$ were calculated at the B3LYP level starting with molecular partition functions developed for computing gas-phase thermodynamics properties within the ideal gas, rigid rotor, and harmonic oscillator approximations at a pressure of 1 atm and a temperature of $298.15 \mathrm{~K}^{[68]}$ This is a standard procedure that has proven to be a correct and useful approach. ${ }^{[69]}$ For each species, Gibbs free energy in solution was determined by adding $\mathrm{G}_{\text {therm }}$ to the highly accurate DLPNO-CCSD(T) energy. Unless stated otherwise, for each reactive process investigated, energies discussed in the following sections are all Gibbs free energies in THF solution referred to the corresponding separate reactants.

In order to shed light on the factors governing the formation of the different products experimentally detected depending on the nucleophilic ligand of the Re complex, we carried out different theoretical analyses on the B3LYP electron density of some of the relevant species. The natural bond orbital $(\mathrm{NBO})^{[70]}$ method was used to obtain net atomic charges (NAC) as implemented in the Gaussian 09 suite of programs. ${ }^{[71]}$ Electron delocalization indexes between two atoms $A$ and $B$ in a molecule, $\delta(A, B)=\mathrm{DI}^{\left[{ }^{[72]}\right.}$ were computed using AIMAll program ${ }^{[73]}$ within the framework of Bader's Atoms in Molecules (AIM) theory. ${ }^{[74]}$ The $\mathrm{DI}$ is a measure of the number of electrons shared between two atoms and therefore, of the covalency of the bond between them.

All B3LYP computations were carried out with the Gaussian 09 suite of programs, ${ }^{[71]}$ while DLPNO-CCSD $(\mathrm{T})$ calculations employed the ORCA program version 4.0.1 ${ }^{[75]}$ and the frozencore approximation. More technical details on the computational chemistry tools mentioned above as well as a justification for the choice of the DLPNO-CCSD $(T)$ method are included in the Supporting Information.

\section{Results and Discussion}

Figure 1 displays the DLPNO-CCSD(T) Gibbs energy profiles obtained for the reaction of $\left[\operatorname{Re}(\mathrm{X})(\mathrm{CO})_{3}(\right.$ bipy) $]$ complexes $(\mathrm{X}=$ $\mathrm{OH}, \mathrm{OMe}, \mathrm{NH} p \mathrm{Tol}, \mathrm{PPh}_{2}$ ) towards HMAD (more details in Tables S1-S16 in the Supporting Information). The labeling of the theoretically located species is in line with the acronyms used in Scheme 2. So, I1 identifies the zwitterionic intermediate formed in the initial attack of the nucleophile ligand on the HMAD acetylenic carbon bearing the $H$ atom (C1). I1' corresponds to an isomer of $\mathbf{I 1}$ wherein the electron lone pair of the acetylenic carbon bearing the $\mathrm{CO}_{2} \mathrm{Me}$ group (C2) is oriented towards the plane defined by $\mathrm{Re}$ and the bipy ligand. Pcco, Pins, and $\mathbf{P} \boldsymbol{c} \boldsymbol{c b}$ are possible products generated through the addition of $\mathrm{C} 2$ to a $\mathrm{CO}$ ligand, the Re atom, and the bipy ligand, respectively. Pccoh is another possible product, only present for $\mathrm{X}=\mathrm{OH}$ and $\mathrm{NH} p$ Tol, which is similar to $\mathrm{Pcco}$ wherein a $\mathrm{H}$ atom of the nucleophile ligand has migrated to the attacked carbonyl ligand. As seen in Figure 1, three different reaction patterns are found. First, for the $\mathrm{OH}$ and $\mathrm{PPh}_{2}$ ligands initial reactive approaches between reactants converge to 11' after passing through I1 via the corresponding TSs TS1 and TS1_1'. From I1' the reaction path splits into three routes giving rise to $\mathbf{P c c o}$, Pins, and Pccb via the TS TS2cco, TS2ins, and TS2ccb, respectively. For $\mathrm{X}=\mathrm{OH}, \mathbf{P c c o}$ undergoes a posterior rearrangement to finally give $P c c o h$. Second, for $X=O M e$ the initial nucleophilic attack also leads to $\mathbf{1 1}$ via TS1 and then transforms into Pcco passing through TS1_1'. Pcco is the splitting structure towards Pins and Pccb now. Third, NHpTol ligand yields a different surface where two approaching orientations of the reactants render separate routes starting both with the attack of the nucleophile ligand on $\mathrm{C} 1$ at HMAD to give the corresponding zwitterions $\mathbf{I 1}$ and $\mathbf{I 1} \mathbf{b}$. At $\mathbf{I} \mathbf{1}$ the $\mathrm{C} 1$-bonded $\mathrm{H}$ atom is oriented to the same side of the complex as the pTol substituent whereas the opposite orientation is found at I1 b (see below). On the one hand, $\mathbf{I 1}$ directly becomes Pcco, which in turn can evolve to either Pins or Pccoh. On the other hand, I1b gives rise to $\mathbf{P} c \boldsymbol{c b}$ after a certain rearrangement.

Let us focus in a comparative way on the formation and rearrangement steps of $\mathbf{I 1}$ (blue line in Figure 1), first, and then on the subsequent routes leading to the addition of the alkyne moiety to $\mathrm{CO}$ (red line in Figure 1), the Re ion in an insertion process (green line in Figure 1), and the bidentate ligand bipy (purple line in Figure 1).

\section{a) Formation and rearrangement of the initial intermediate}

According to Figure 1, for the reaction of the complexes with $\mathrm{X}=$ $\mathrm{OH}$ and $\mathrm{OMe}$, the TS for the attack of the $\mathrm{X}$ ligand to $\mathrm{C} 1, \mathrm{TS} 1$, leading to I1 competes with the TS for the rearrangement of this intermediate, TS1_1', for being the rate limiting step. In the case of the complexes containing $\mathrm{X}=\mathrm{NH} p$ Tol and $\mathrm{PPh}_{2}$, TS1 is clearly less stable than TS1_1' and ends up being the rate limiting TS. As mentioned above, the complex with $\mathrm{NH} p \mathrm{Tol}$, presents an alternative reactive approach of the reactants, which is controlled by TS1b, a TS analogous to TS1. Both TSs present similar relative energies, but the TS1-controlled route leads to the very stable product $\mathbf{P c c o h}$, the one detected experimentally, while the TS1b-controlled route gives rise to $\mathbf{P c c b}$, which is 14.5 $\mathrm{kcal} / \mathrm{mol}$ less stable than Pccoh. Therefore, in this scenario, we focus on conducting a detailed comparative analysis of the TS1 species found for the four complexes (see optimized geometries at Figure 2). The route leading to $\mathbf{P c c b}$ when $\mathrm{X}=\mathrm{NH} p$ Tol will be described afterwards.

The energy barrier determined by TS1 increases from $\mathrm{PPh}_{2}$ $(17.5 \mathrm{kcal} / \mathrm{mol})$ to $\mathrm{NH} p \mathrm{Tol}(22.4 \mathrm{kcal} / \mathrm{mol}), \mathrm{OMe}(25.9 \mathrm{kcal} / \mathrm{mol})$, and $\mathrm{OH}(27.0 \mathrm{kcal} / \mathrm{mol})$, in good agreement with the well-known observation that large atoms are more easily polarizable, and by extension more nucleophilic than small ones. However, the size of the attacking atom is not the only feature affecting the barrier of the nucleophilic attack. The energy of the HOMO of a nucleophile is directly related to its nucleophilicity, being better nucleophiles those with the largest energy HOMOs (considering the sign). For the initial $\left[\operatorname{Re}(\mathrm{X})(\mathrm{CO})_{3}(\mathrm{bipy})\right]$ complexes $(\mathrm{X}=\mathrm{OH}$, 

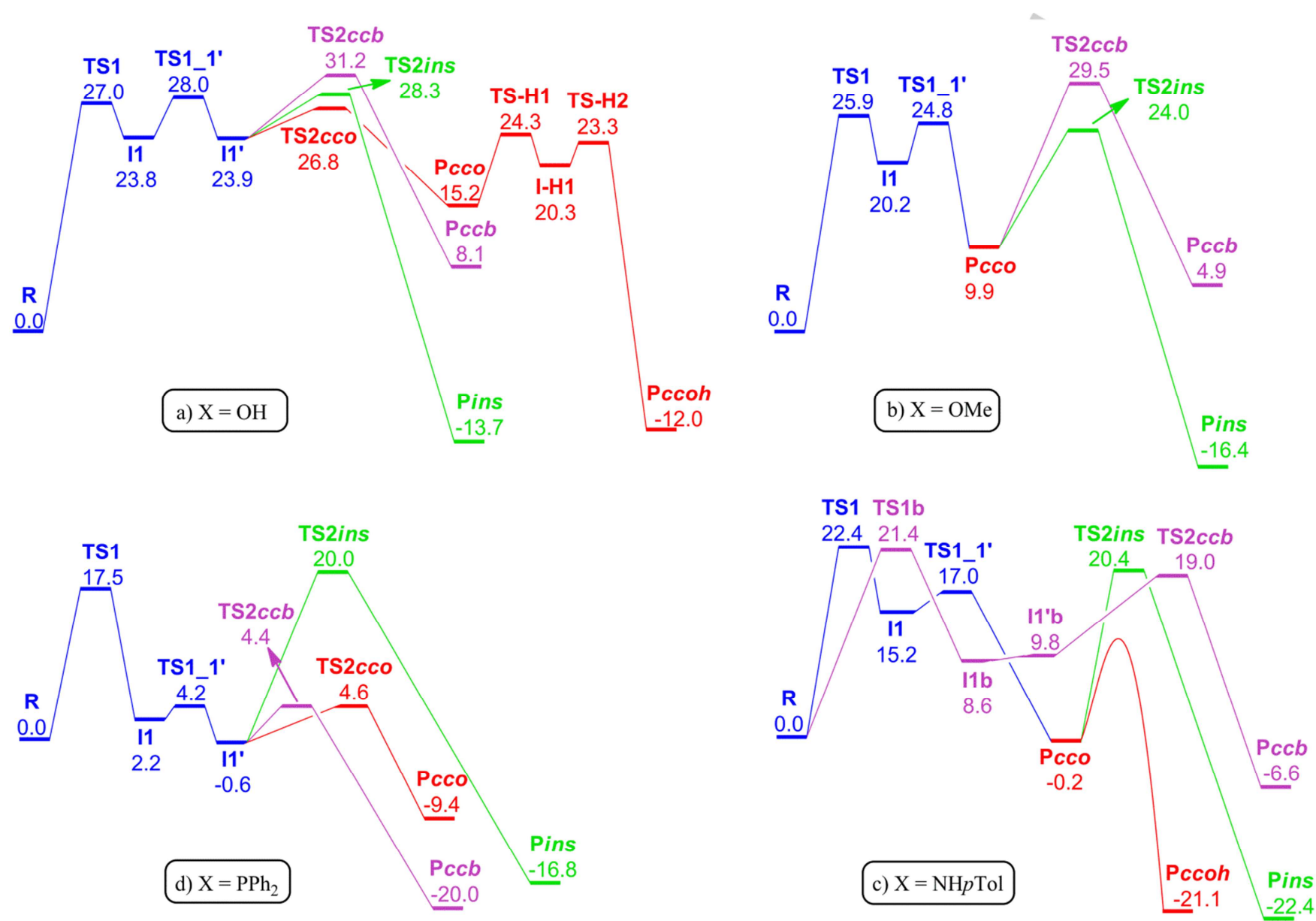

Figure 1. DLPNO-CCSD(T) Gibbs energy profiles in kcal/mol for the reaction of $\left[\operatorname{Re}(X)(C O)_{3}(\right.$ bipy $\left.)\right]$ with $\mathrm{HMAD}$, being $\left.\left.\mathrm{X}=\mathrm{a}\right) \mathrm{OH}, \mathrm{b}\right) \mathrm{OMe}$, c) $\mathrm{NH} p \mathrm{Tol}$, and d) $\mathrm{PPh}{ }_{2}$. For Pcco and Pccoh species with $\mathrm{X}=\mathrm{NH}$ pTol, an approximate connectivity is shown (see text).

OMe, NHpTol, $\mathrm{PPh}_{2}$ ), $\mathbf{C}$ in Figure 2, HOMO energies are -0.162 (NHpTol), -0.186 $\left(\mathrm{PPh}_{2}\right),-0.199(\mathrm{OMe})$, and $-0.208(\mathrm{OH})$, all in $\mathrm{eV}$. As seen in Figure 3, the greater stability of the HOMO of the complexes containing $\mathrm{OH}$ and $\mathrm{OMe}$ can be ascribed to the presence of a notable stabilizing interaction found between a $d$ type orbital of $\operatorname{Re}$ and one of the $\pi^{*}$ antibonding orbitals of the $\mathrm{CO}$ ligand trans to nucleophile ligand. This kind of interaction is notably reduced for complexes containing $\mathrm{NHpTol}$ and $\mathrm{PPh}_{2}$. More interestingly, the HOMO energy sequence aforementioned matches the trend in the barriers computationally obtained except when comparing $\mathrm{NH}$ pTol and $\mathrm{PPh}_{2}$ with each other. HOMO energies can be understood as a measurement of the general nucleophilicity of the whole complex, where $\mathrm{X}$ is one of the ligands. However, electron donation takes place from a particular atom, so the availability of the electron density at this atom is a matter of concern. For the Re complex with $\mathrm{X}=$ $\mathrm{NHpTol}$ the sum of the three angles centered on $\mathrm{N}$ is $359.5^{\circ}$, representative of a planar distribution of groups around $\mathrm{N}$, in good agreement with the value of $359.8^{\circ}$ obtained from X-ray data. ${ }^{[49]}$ The same sum of angles for the complex with $\mathrm{X}=\mathrm{PPh}_{2}$ amounts to $319.3^{\circ}$, far from a planar coordination around $P$ (see Figure 2). Both $N$ and $P$ ligands have at least one aromatic group bonded to them. Thanks to the planar coordination and the similar atomic size, the lone pair of the $\mathrm{N}$ atom is conjugated with the $p$ Tol group, so it is less available for a nucleophilic attack than in the case of the $\mathrm{P}$ ligand, where no conjugation between the electron density of the large $P$ atom and any of the $\mathrm{Ph}$ groups is present. Actually, the resonance electronic structures where the aromaticity of the pTol ligand is lost contribute to the energy destabilization of the HOMO of the $\mathrm{NH} p$ Tol ligand. The shape of the HOMO of these two complexes shows the availability of the lone pair of the nucleophile ligand in agreement with previous discussion. As seen in Figure 3, for the complex with $\mathrm{PPh}_{2}, \mathrm{HOMO}$ is mainly described by the $p$ orbital of the $\mathrm{P}$ atom while the one containing $\mathrm{NHpTol}$, the $p$ orbital of the $\mathrm{N}$ atom is combined with one of the $\pi$ bonding orbitals of the pTol substituent. 

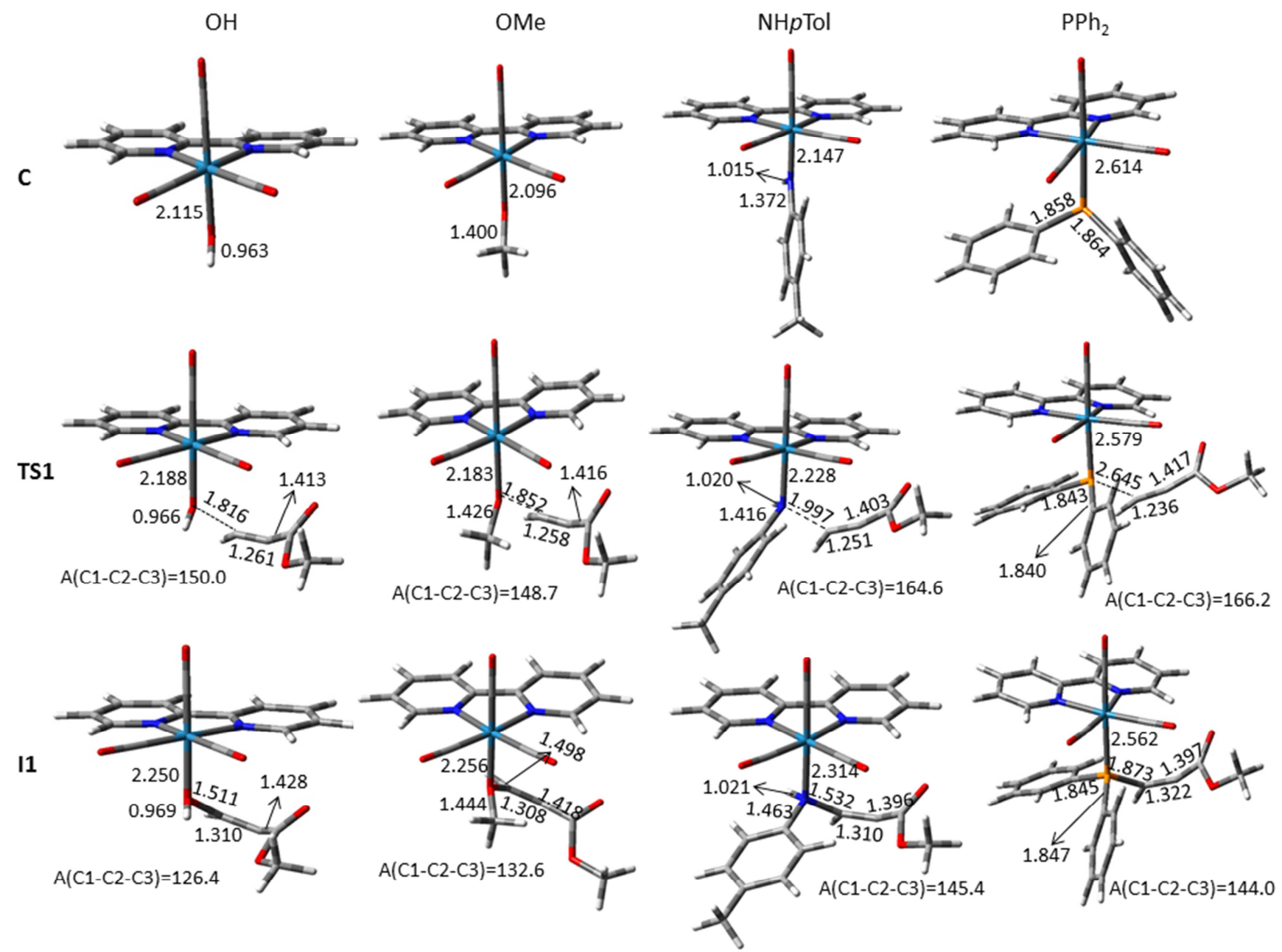

Figure 2. B3LYP optimized structures of the initial $\left[\mathrm{Re}(\mathrm{X})(\mathrm{CO})_{3}(\mathrm{bipy})\right]$ complexes $\left(\mathrm{X}=\mathrm{OH}, \mathrm{OMe}, \mathrm{NH} p T o l, \mathrm{PPh}_{2}\right)$, $\mathrm{C}$, and the species involved in their nucleophilic attack to HMAD. Relevant bond distances in angstroms and bond angles involving the carbon skeleton of the HMAD moiety, $\mathrm{A}\left(\mathrm{HC}(1)=\mathrm{C}(2)-\mathrm{C}(3) \mathrm{OOCH} \mathrm{C}_{3}\right)=\mathrm{A}(\mathrm{C} 1-$ C2-C3), in degrees are given.

The stability of $\mathbf{I 1}$ with respect to TS1 amounts to $3.2,5.7,7.2$, and $15.3 \mathrm{kcal} / \mathrm{mol}$ for $\left[\operatorname{Re}(\mathrm{X})(\mathrm{CO})_{3}(\right.$ bipy $\left.)\right]$ complexes with $\mathrm{X}=\mathrm{OH}$, $\mathrm{OMe}, \mathrm{NH} p \mathrm{Tol}$, and $\mathrm{PPh}_{2}$, respectively. In this intermediate some electron density has been transferred from the nucleophilic atom of the $\mathrm{X}$ ligand to the alkyne $(0.275 \mathrm{e}$ from $\mathrm{O}$ in the $\mathrm{OH}$ complex, 0.184 e from $\mathrm{O}$ in the $\mathrm{OMe}$ complex, 0.137 e from $\mathrm{N}$, and 0.654 $e$ from $\mathrm{P}$, according to NBO population (see Figure $\mathrm{S} 1$ in the Supporting Information)) in such a way that a concentration of electron density at $\mathrm{C} 2$ has taken place $(\mathrm{NAC}(\mathrm{C} 2)=-0.404$ e for $\mathrm{OH}$ complex, -0.388 e for OMe complex, -0.317 e for $\mathrm{NHpTol}$ complex, and -0.245 e for $\mathrm{PPh}_{2}$ complex). At $\mathbf{1 1}$ the incipient lone pair at $\mathrm{C} 2$ is in trans disposition with respect to the attacking nucleophilic atom and needs to be reoriented towards the equatorial plane of the $\overline{R e}$ complex where electrophilic positions are placed (see Figure 2). This is done through TS1_1', a broad allene-like TS in the corresponding PES that is 4.2, 4.6, 1.8, and $2.0 \mathrm{kcal} / \mathrm{mol}$ larger in energy than $\mathbf{I} \mathbf{1}$ (see Figures 1 and 4 ) for $X$
$=\mathrm{OH}, \mathrm{OMe}, \mathrm{NH} p \mathrm{Tol}$, and $\mathrm{PPh}_{2}$, respectively. As already said, complexes with $\mathrm{OH}$ and $\mathrm{PPh}_{2}$ ligands present I1' corresponding to a kind of zwitterion stereoisomer of $\mathbf{I 1}$ with the lone pair at C2 in cis position with respect to the attacking nucleophilic atom (see Figure 4). NBO charges indicate that both $\mathrm{N}$ and $\mathrm{P}$ lose electron density when evolving from the initial complexes to I1 and then to I1', when present. At I1 with $\mathrm{PPh}_{2}$ the charge mainly concentrates at $\mathrm{C} 1$ of $\mathrm{HMAD}(\mathrm{NAC}(\mathrm{C} 1)=-0.637 e, \mathrm{NAC}(\mathrm{C} 2)=-$ $0.245 e)$, whereas with $\mathrm{OH}(\mathrm{NAC}(\mathrm{C} 1)=-0.059 e, \mathrm{NAC}(\mathrm{C} 2)=-$ $0.404 e)$, OMe $(\operatorname{NAC}(\mathrm{C} 1)=-0.047 e, \operatorname{NAC}(\mathrm{C} 2)=-0.388 e)$, and $\mathrm{NHpTol}(\mathrm{NAC}(\mathrm{C} 1)=-0.154 e, \operatorname{NAC}(\mathrm{C} 2)=-0.317 e$, ) the electron density is pushed towards $\mathrm{C} 2$. However, we note that for the latter the charge concentration at $\mathrm{C} 1$ is notably greater than that for the $\mathrm{O}$ ligands. For the $\mathrm{OMe}$ and $\mathrm{NH}$ pTol ligands an exhaustive search through IRC calculations from TS1_1' failed to find a similar I1' intermediate but led the system to Pcco. This particular region of PES seems to be very sensitive to $X$. 


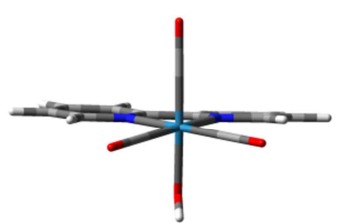

a) $\mathrm{X}=\mathrm{OH}$

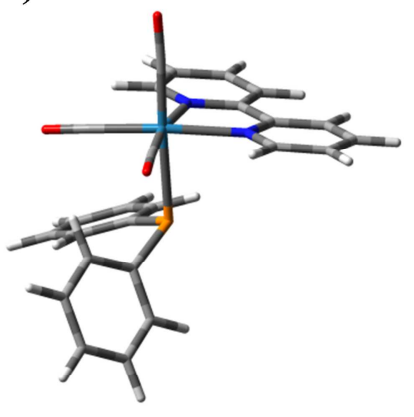

d) $\mathrm{X}=\mathrm{PPh}_{2}$
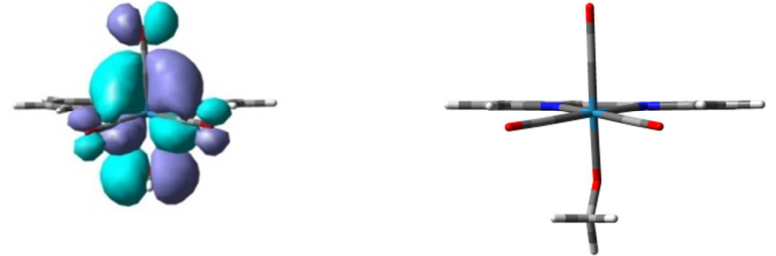

b) $\mathrm{X}=\mathrm{OMe}$
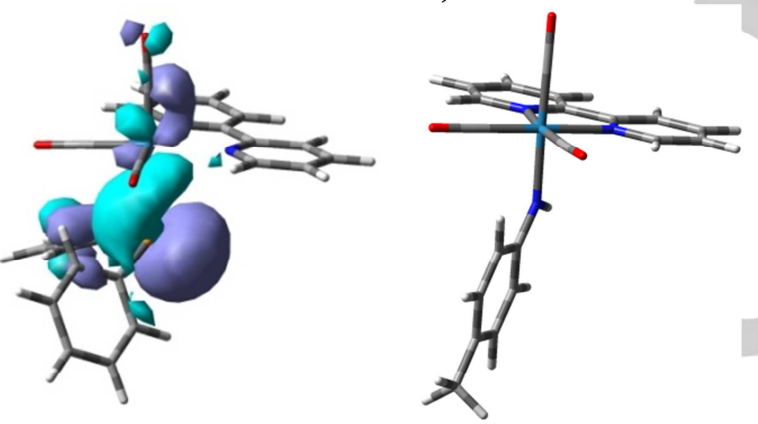

c) $\mathrm{X}=\mathrm{NH} p \mathrm{Tol}$
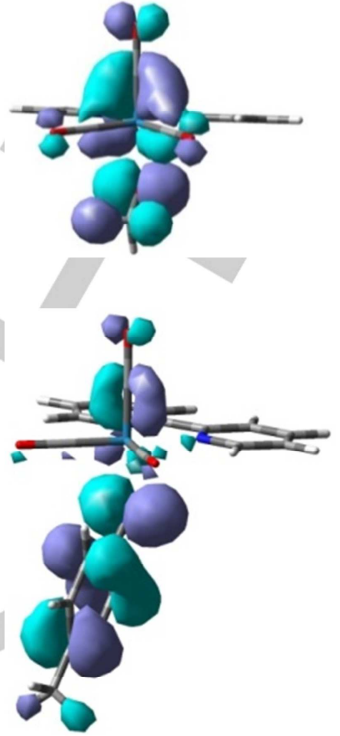

Figure 3. Shape of the HOMOs for $\left[\operatorname{Re}(X)(C O)_{3}(\right.$ bipy)] complexes with $X=a) O H$, b) OMe, c) $\mathrm{NH} p T o l$, and d) $\mathrm{PPh}_{2}$.
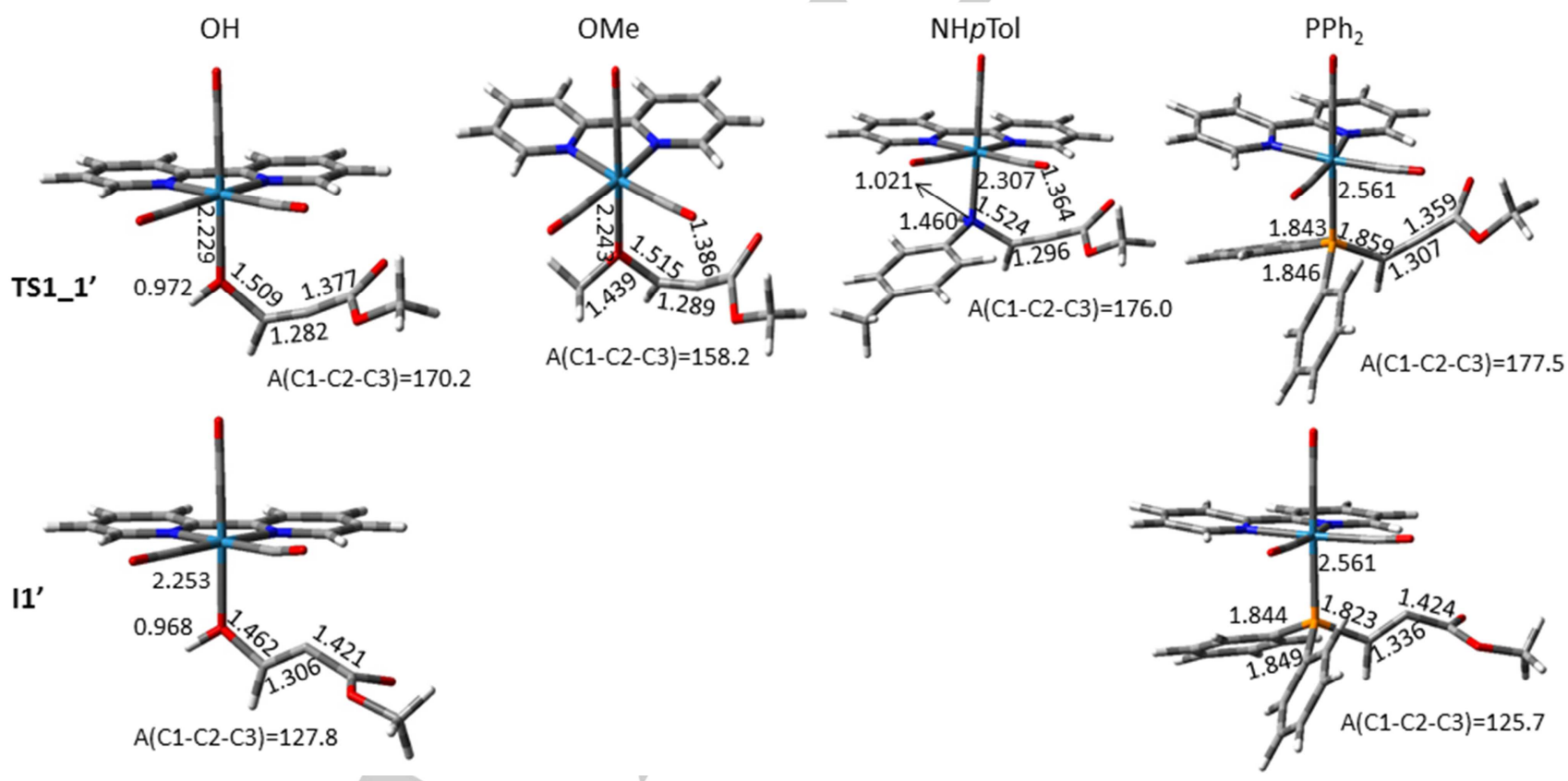

Figure 4. B3LYP optimized structures of TS1_1' and I1' (when present) for the reaction of $\left.\left[\mathrm{Re}(\mathrm{X})(\mathrm{CO})_{3}(\mathrm{bipy})\right](\mathrm{X}=\mathrm{OH}, \mathrm{OMe}, \mathrm{NH} p \mathrm{Tol}, \mathrm{and} \mathrm{PPh})_{2}\right)$ towards $\mathrm{HMAD}$. Relevant bond distances in angstroms and bond angles involving the carbon skeleton of the $\mathrm{HMAD}$ moiety, $A(\mathrm{HC}(1) \equiv \mathrm{C}(2)-\mathrm{C}(3) \mathrm{OOCH})_{3}=\mathrm{A}(\mathrm{C} 1-\mathrm{C} 2-\mathrm{C} 3)$, in degrees are given.

\section{b) Addition of the alkyne moiety to a CO ligand}

As displayed in Figure 1, I1' becomes Pcco through the TS TS2cco for the $\mathrm{OH}$ and $\mathrm{PPh}_{2}$ ligands. However, Pcco is obtained from I1 via TS1_1' for OMe and NHpTol. Moreover, for these ligands, I1' and TS2cco could not be detected after an extensive search.
TS2cco is for the C-C coupling between C2 and a CO ligand in cis with respect to the attacking nucleophilic ligand, which leads to the formation of a five-membered ring in a new bidentate ligand. It presents a low barrier of $2.9 \mathrm{kcal} / \mathrm{mol}(\mathrm{OH})$ and $5.2 \mathrm{kcal} / \mathrm{mol}\left(\mathrm{PPh}_{2}\right)$, when measured from I1'. According to NBO charges, the $\mathrm{CO}$ ligand in cis disposition with respect to the alkyne moiety is a strong electrophile due to the large positive 


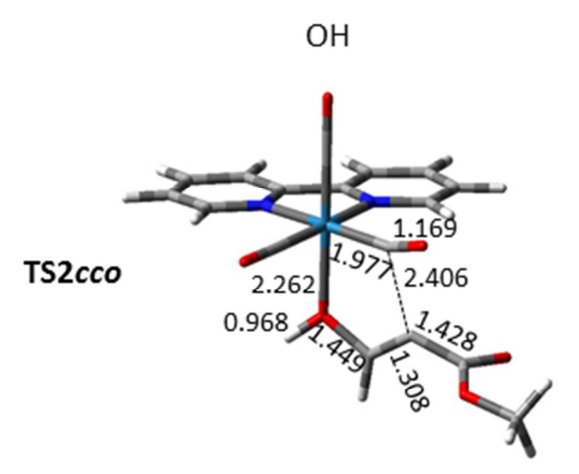

OMe

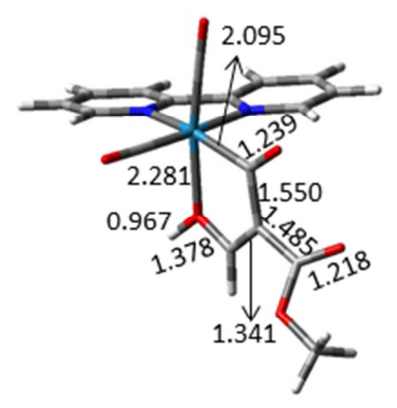

Pcco

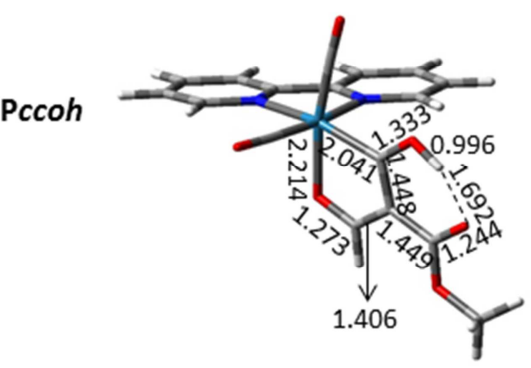

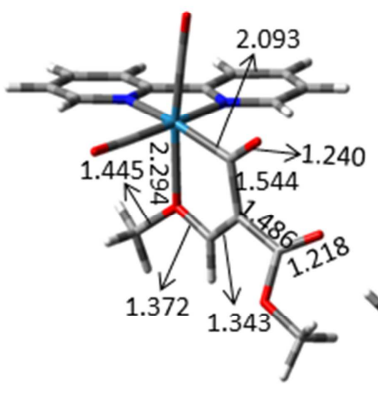
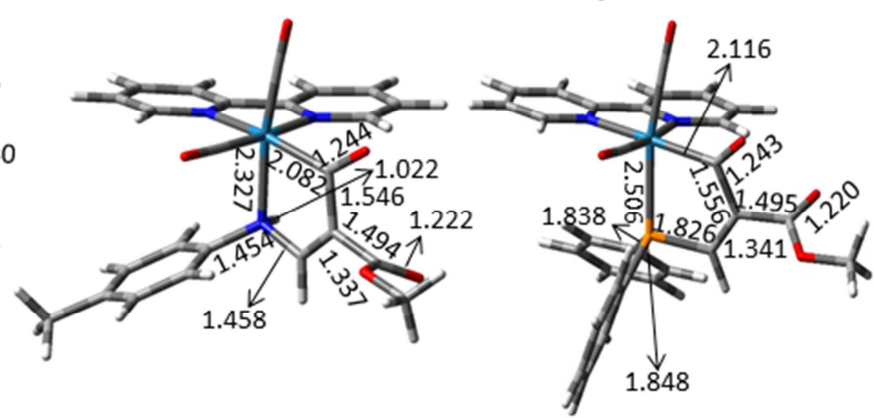

$\mathrm{NH} p \mathrm{Tol}$
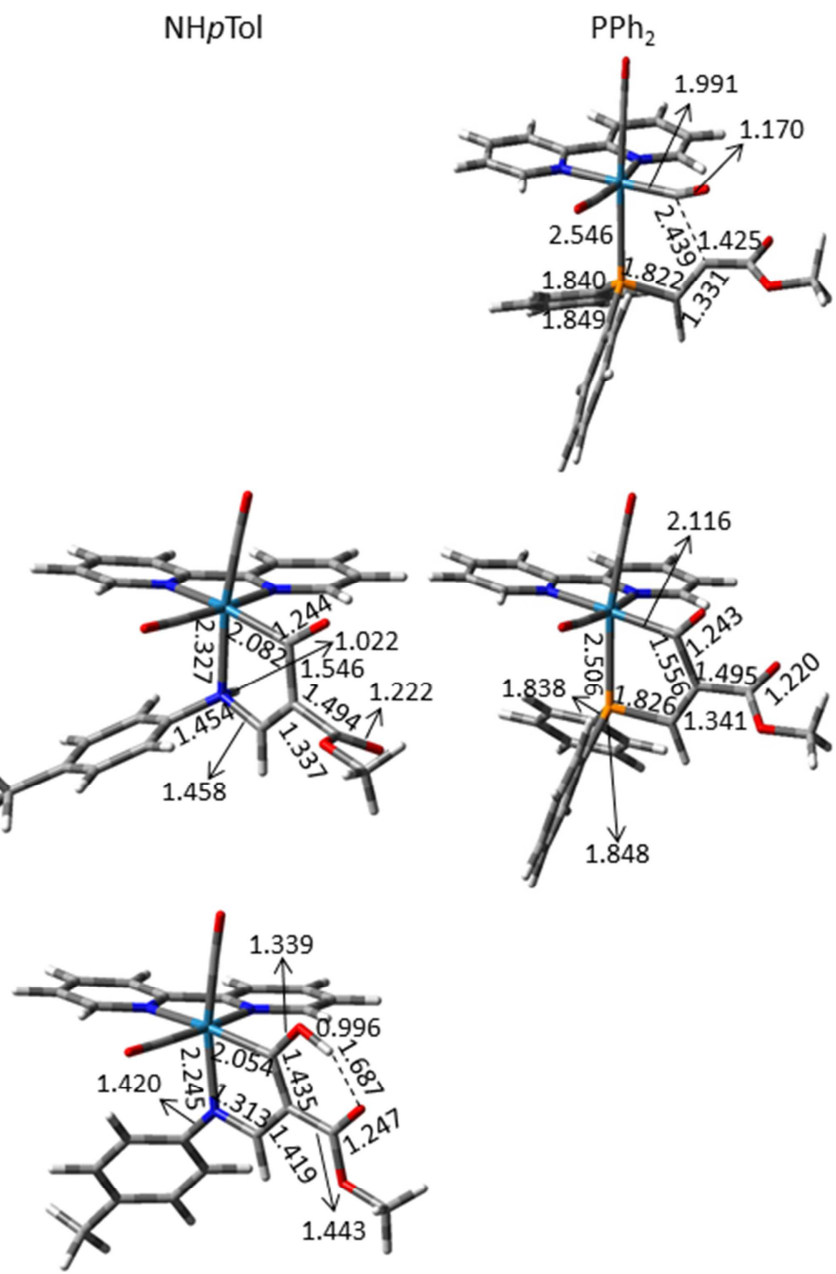

Figure 5. B3LYP optimized structures of TS2cco, $\mathbf{P c c o}$, and $\mathbf{P c c o h}$ (when present) for the reaction of $\left[\mathrm{Re}(\mathrm{X})(\mathrm{CO})_{3}(\mathrm{bipy})\right]\left(\mathrm{X}=\mathrm{OH}, \mathrm{OMe}, \mathrm{NH} p T\right.$ ol, and $\left.\mathrm{PPh} \mathrm{H}_{2}\right)$ towards HMAD. Relevant bond lengths in angstroms are displayed.

charge on its $\mathrm{C}$ atom $\left(0.730\right.$ and 0.756 e for $\mathrm{OH}$ and $\mathrm{PPh}_{2}$ ligands at I1', respectively). As seen in Figure 5, both of them are early TSs where the new C2-CO bond is still long (2.406 and $2.439 \AA$ for $\mathrm{OH}$ and $\mathrm{PPh}_{2}$, respectively) and the triple $\mathrm{C} 1-\mathrm{C} 2$ bond still short (1.308 and $1.331 \AA$ for $\mathrm{OH}$ and $\mathrm{PPh}_{2}$, respectively). Geometrically, $\mathrm{CO}$ is close to the attacking $\mathrm{C} 2$ atom, so both electronic and steric factors point to a small barrier, as it is indeed.

At Pcco the alkyne moiety has been fully incorporated to the Re complex through its $\mathrm{C} 1-\mathrm{C} 2$ bond yielding the new fivemembered metallacycle (see Figure 5). The Gibbs energy of $\mathbf{P c c o}$ is larger than that of isolated reactants for $\mathrm{OH}(15.2$ $\mathrm{kcal} / \mathrm{mol})$ and OMe $(9.9 \mathrm{kcal} / \mathrm{mol})$ complexes, but smaller for $\mathrm{NH}$ Tol $(-0.2 \mathrm{kcal} / \mathrm{mol})$ and $\mathrm{PPh}_{2}(-9.4 \mathrm{kcal} / \mathrm{mol})$ complexes. It is interesting to note that the $\mathrm{Re}-\mathrm{X}$ distance at $\mathbf{P c c o}$ is about $8.5 \%$ longer than in isolated reactants for $\mathrm{OH}, \mathrm{OMe}$, and $\mathrm{NHpTol}$ ligands, whereas it becomes reduced by about $4 \%$ at Pcco for the $\mathrm{PPh}_{2}$ complex. The strengthening of the Re-P bond seems to provide extra stability to this last $\mathbf{P c c o}$ product. In the case of $\mathrm{Re}(\mathrm{I})$ complexes with the $\mathrm{OH}$ and $\mathrm{NHpTol}$ ligands, both containing a $\mathrm{H}$ atom bonded to a nucleophilic atom, Pcco evolves to a new product where that $\mathrm{H}$ atom has migrated to the $\mathrm{O}$ atom of the attacked $\mathrm{CO}$ ligand (see Pccoh in Figure 5). The transformation $\mathbf{P c c o} \rightarrow \mathbf{P c c o h}$ could occur via an intramolecular hydrogen shift. Several options were considered, but none of them proved feasible (see discussion and Figure S2 in the Supporting Information), so, we figured it could take place through an intermolecular hydrogen shift. Figure 6 displays the main structures located for the $\mathrm{OH}$ ligand and Tables S5-S7 collect their energy data. The process starts with the species Pcco_dimer where two Pcco moieties oriented themselves with the $\mathrm{H}$ atoms of the $\mathrm{OH}$ ligands heading to the carbonyl oxygen atoms of the ester groups of the opposite molecule. Then, TSH1 performs the simultaneous transfer of both $\mathrm{H}$ atoms with a Gibbs energy barrier of $9.1 \mathrm{kcal} / \mathrm{mol}$ from Pcco_dimer to give rise to intermediate $\mathbf{I 0 - H 1}$, where the carboxylate groups hold 
the travelling hydrogen atoms at a distance of $1.010 \AA$. From I0H1 several low energy demanding rearrangements place the transferred $\mathrm{H}$ atom closer to the attacked carbonyl ligand, as shown in the monomer species I-H1. Finally, the last step in the $\mathrm{H}$ migration occurs through TS-H2 where the migrated hydrogen rotates and transfers to the target $\mathrm{CO}$, leading to a new stabilizing $\mathrm{H}$-bond with the ester group. Geometrically, the metallacyle at Pccoh products is tighter than that at the corresponding Pcco previous species (see Figure 5). Only the $\mathrm{C} 1-\mathrm{C} 2$ bond slightly elongates. These issues, along with the absence of charges of Pccoh products, make them the second most stable ones (after Pins) for the reaction of these complexes $(-12.0$ and $-21.1 \mathrm{kcal} / \mathrm{mol}$ for $\mathrm{OH}$ and $\mathrm{NH} p$ Tol ligands, respectively). Analogous dimer intermediates and reaction path are assumed to describe the $\mathrm{H}$ transfer between Pcco and Pccoh for the complex with NHpTol. Although the notable size of the dimer systems containing this ligand prevents the performance of the very demanding DLPNO-CCSD(T) calculations, the similarity of the species found for the intramolecular hydrogen migration to those for the $\mathrm{OH}$ ligand seems to validate our assumption (see Supporting Information).

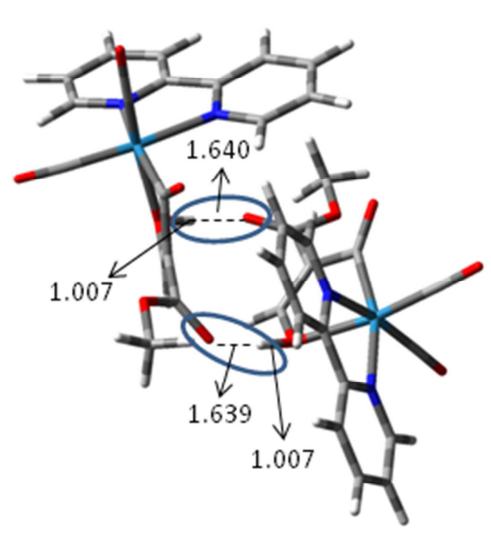

Pcco_dimer

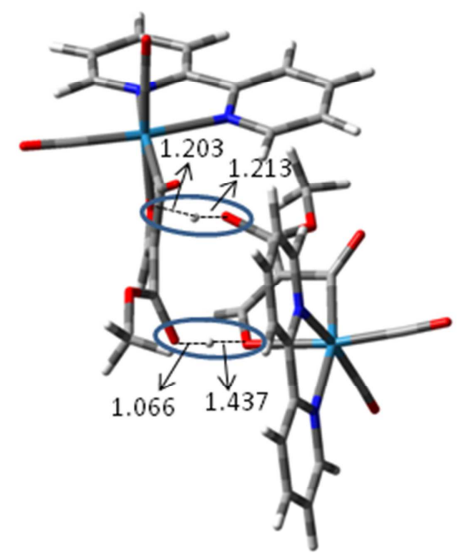

TS-H1

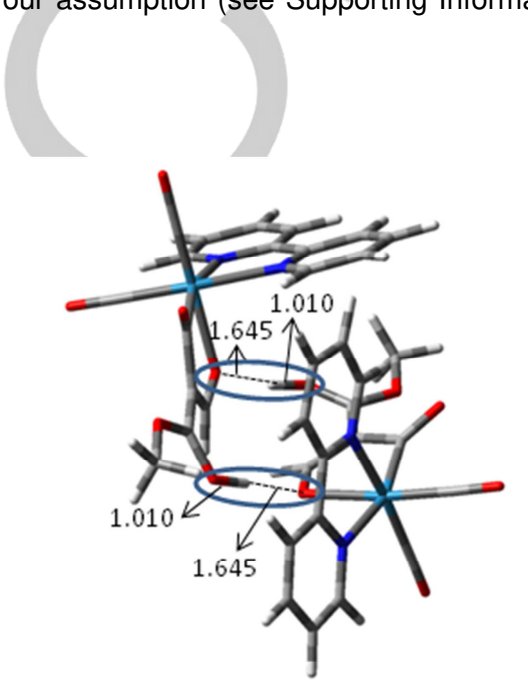

I0-H1

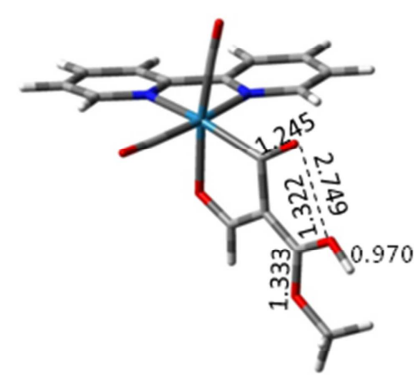

$\mathrm{I}-\mathrm{H} 1$

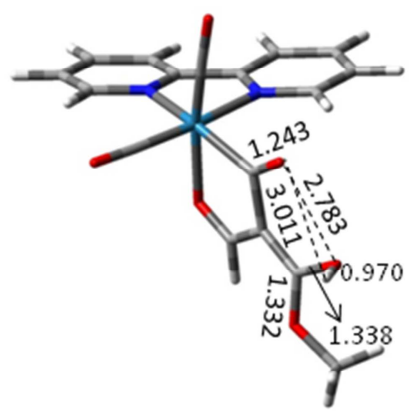

TS-H2

Figure 6. B3LYP optimized structures for the $\mathrm{H}$ transpositions from the $\mathrm{OH}$ ligands to the carbonyl oxygen atoms in the $\mathrm{Pcco}$ structures. Relevant bond lengths in angstroms are displayed.

c) Addition of the alkyne moiety to the Re atom: the ins route

The C2 atom of either I1' or Pcco species could also bond to the Re metal evolving through TS2ins (see Figure 7). At the intermediates previous to TS2ins the corresponding $\mathrm{Re}-\mathrm{X}$ bond is strong and starts weakening when the new C2-Re bond begins to form during the concerted synchronous process characterized by TS2ins. For the complex with $\mathrm{X}=\mathrm{OH}$, the barrier for TS2ins is just $4.4 \mathrm{kcal} / \mathrm{mol}$, from I1'. Such a small value indicates that the energy released from the partial formation of the new C2-Re bond nearly compensates for the cost of breaking the Re-O bond. A different situation appears for the complex with $\mathrm{X}=\mathrm{PPh}_{2}$, where the barrier for TS2ins raises to $20.6 \mathrm{kcal} / \mathrm{mol}$ from its previous intermediate, 11'. This means that the Re-P bond is much stronger than the bond formed between $\mathrm{Re}$ and $\mathrm{O}$ in the $\mathrm{X}=\mathrm{OH}$ complex considered here. Actually, the DI shows a value of 0.614 for the Re-P bond, notably larger than that found for the Re-O one (0.374). The $d$ orbitals in a third-row atom, like phosphorous, are better sized to largely overlap with $\mathrm{Re}$ ones than second-row atoms. This 
makes the insertion path very unlikely for the complex with the $\mathrm{PPh}_{2}$ ligand. On the other hand, in complexes with $\mathrm{X}=\mathrm{OMe}$ and $\mathrm{NHpTol}$ IRC calculations clearly demonstrate that Pcco is the structure preceding TS2ins, with a barrier of 14.1 and 20.6 $\mathrm{kcal} / \mathrm{mol}$ respectively, measured from it. These large values come from the fact that two bond breakages are needed to accomplish the insertion, the $\mathrm{Re}-\mathrm{O}$ or $\mathrm{Re}-\mathrm{N}$ and the $\mathrm{C} 2-\mathrm{CO}$ ones. The products formed at the end of this reaction path are $Z$ alkenyl complexes with no charge separation. This explains why this type of products is more stable than reactants (between 13 and $17 \mathrm{kcal} / \mathrm{mol}$ for $\mathrm{OH}, \mathrm{OMe}$, and $\mathrm{PPh}_{2}$ systems and 22.4 $\mathrm{kcal} / \mathrm{mol}$ for $\mathrm{NHpTol})$. In the case of $\mathrm{NHpTol}$ the aromatic ring bonded to the $\mathrm{N}$ atom is placed far away from the complex equatorial ligands, thus avoiding repulsive interactions present in the remaining structures of its reaction profile. It has been reported that, when the insertion product is the main one, addition of an acid like HTOf in $\mathrm{CDCl}_{3}$ allows the release of the corresponding Z-alkenyl complex with $\mathrm{H}$ replacing the metal. ${ }^{[47]}$
TS2ins
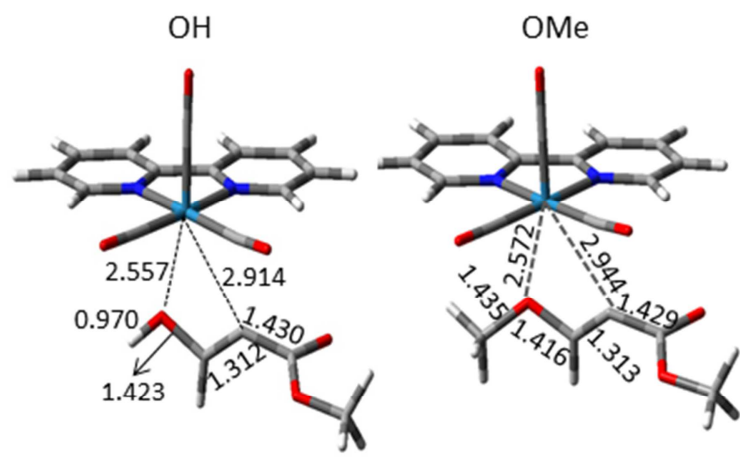

Pins
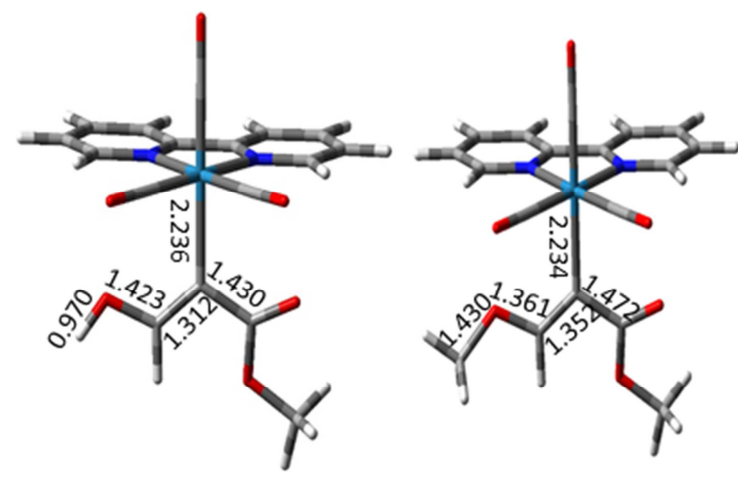

$\mathrm{NH} p \mathrm{Tol}$
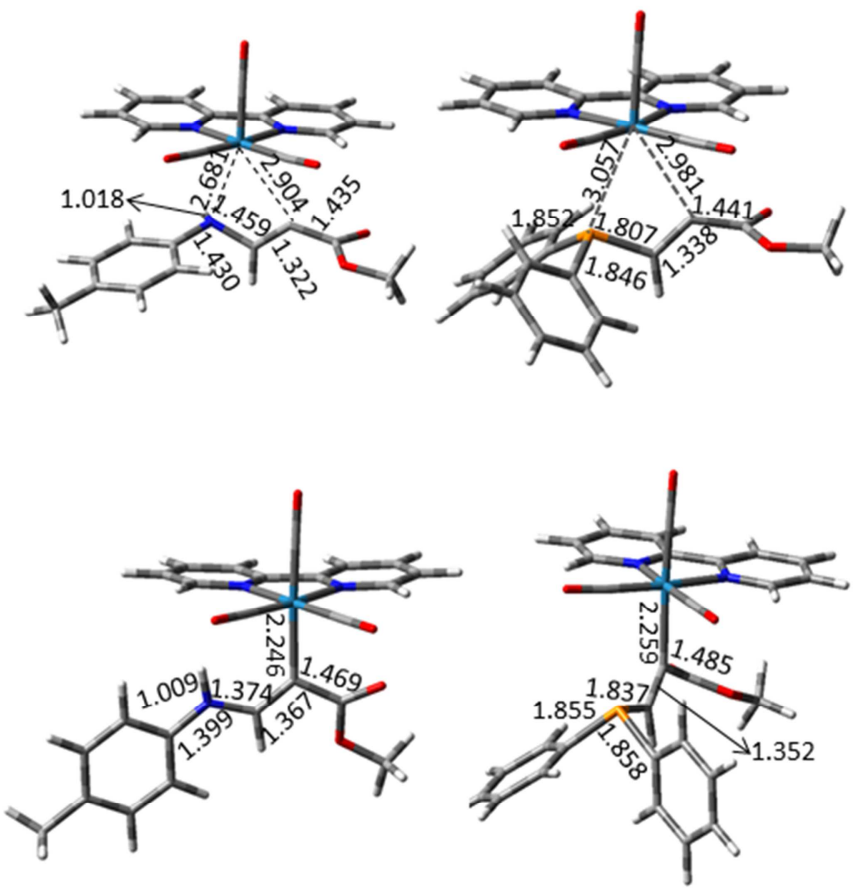

Figure 7. B3LYP optimized structures of the species involved in the addition step to the $\operatorname{Re}$ atom for the reaction of $\left[\operatorname{Re}(\mathrm{X})(\mathrm{CO})_{3}(\mathrm{bipy})\right](\mathrm{X}=\mathrm{OH}, \mathrm{OMe}, \mathrm{NHpTol}$, and $\mathrm{PPh}_{2}$ ) towards HMAD. Relevant bond lengths in angstroms are shown.

\section{d) Addition of the alkyne moiety to the bipy ligand}

Although hardly electrophilic, one of the ortho $\mathrm{C}$ atoms bearing a hydrogen at the bipy ligand, C6, could also be attacked by the C2 alkyne atom, as it was experimentally observed for the complex with $\mathrm{PPh}_{2}$ ligand. ${ }^{[51,52]}$ TS2ccb represents this addition and has been theoretically characterized for the four complexes here considered (see Figures 8 and 9). However, three different reaction paths are computationally observed for the formation of Pccb. As for TS2ins, TS2ccb may come from I1' (complexes with $\mathrm{X}=\mathrm{OH}$ and $\mathrm{PPh}_{2}$ ) or Pcco (complex with $\mathrm{X}=\mathrm{OMe}$ ). However, for the complex with $\mathrm{X}=\mathrm{NH} p$ Tol IRC calculations indicate that a slightly different zwitterion, $\mathbf{I 1} \mathbf{b} \mathbf{b}$, is preceding TS2ccb. At I1'b the C1-bonded hydrogen atom of the alkyne moiety $(\mathrm{H} 1)$ is placed outwards with respect to the bidentate ligand (see Figure 8), which suggests an approach of the reactants different from that considered so far. Actually, leaving
$\mathrm{H} 1$ outwards at the initial interaction between reactants leads to a TS, TS1b, with nearly the same energy as TS1 that evolves to I1b (see Figure 8). This intermediate resembles $\mathbf{I 1}$ in the sense that the lone pair that starts forming at $\mathrm{C} 2$ is in trans disposition with respect to the attacking $\mathrm{N}$ atom, but $\mathbf{I 1 b}$ is $6.6 \mathrm{kcal} / \mathrm{mol}$ more stable than I1. No TS but a steadily decreasing energy path joins I1 $\mathbf{b}$ with $\mathbf{1} \mathbf{1} \mathbf{b}$, where the lone pair at $\mathrm{C} 2$ is in cis orientation with respect to the nucleophilic $\mathrm{N}$ atom. I1'b resembles intermediates I1' found for the rest of complexes in the sense that some electron density concentrates on the $\mathrm{C} 2$ atom of the alkyne $(-0.422 \mathrm{e})$ and faces towards the electron poor area of the equatorial ligands. However, C2 electron charge is pointing to bipy in a more tilted way than in the remaining I1' intermediates. I1'b, with a relative Gibbs energy of $9.8 \mathrm{kcal} / \mathrm{mol}$, evolves to TS2 $c \boldsymbol{c b}$ and finally to Pccb. The 


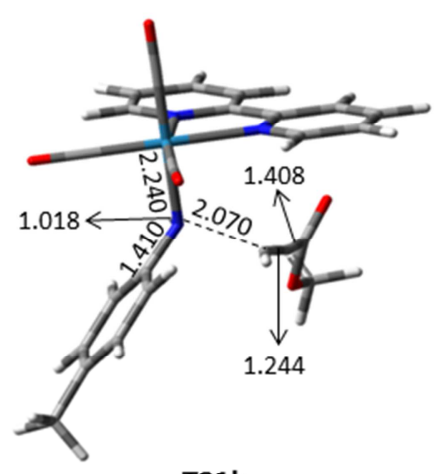

TS1b

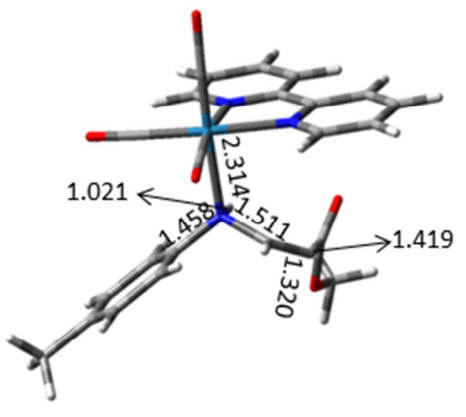

I1b

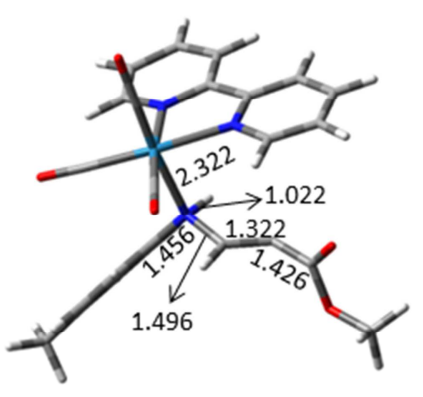

I1'b

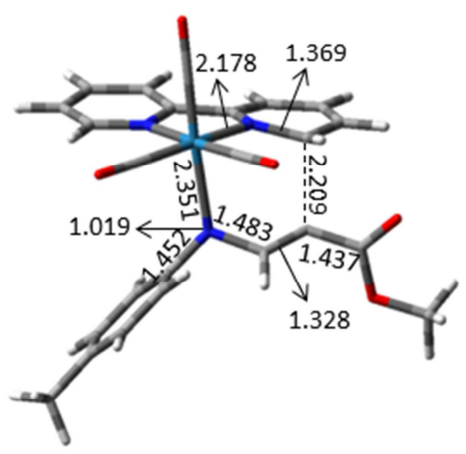

$\mathrm{TS} 2 c \boldsymbol{c} b$

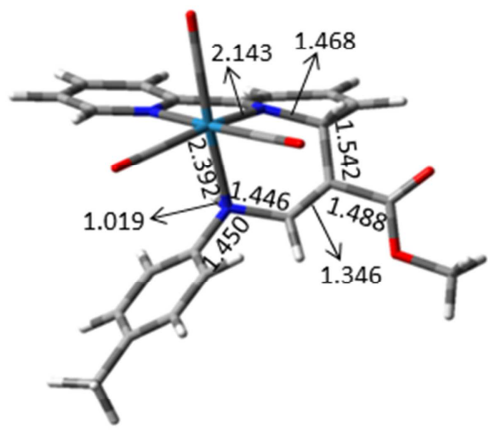

Pccb

Figure 8. B3LYP optimized structures for the reaction of $\left[\operatorname{Re}\left(\mathrm{NH}_{\mathrm{N} T \mathrm{Ol}}\right)(\mathrm{CO})_{3}(\right.$ bipy $\left.)\right]$ with $\mathrm{HMAD}$ to yield $\mathrm{Pccb}$. Some relevant distances in angstroms are given.
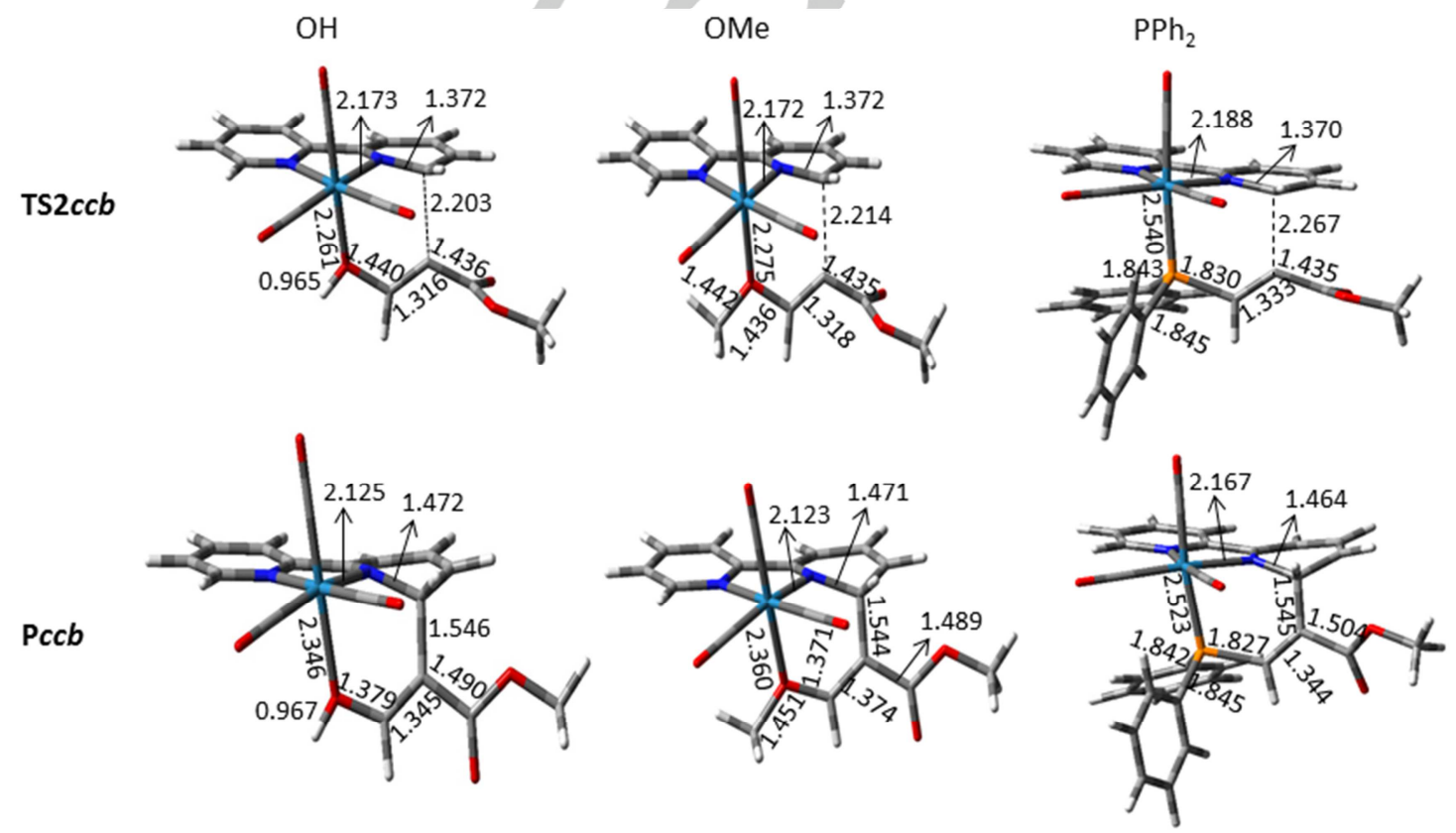

Figure 9. B3LYP optimized structures of the species implied in the addition step of the alkyne moiety to the bipy ligand for the reaction of $\left[\operatorname{Re}(\mathrm{X})(\mathrm{CO})_{3}(\mathrm{bipy})\right](\mathrm{X}=$ $\mathrm{OH}, \mathrm{OMe}$, and $\mathrm{PPh}_{2}$ ) towards HMAD. Relevant bond distances in angstroms are shown. 
approach of HMAD to $\mathrm{H} 1$ in the outward orientation was also found for the rest of the complexes, but did not link to the routes leading to the experimentally observed products.

For complexes with $\mathrm{NHpTol}$ and mainly for those with $\mathrm{OH}$ and OMe ligands, the barrier of TS2 ccb is large when measured from the reactants $(31.2,29.5$, and $19.0 \mathrm{kcal} / \mathrm{mol}$ for $\mathrm{OH}, \mathrm{OMe}$, and $\mathrm{NHpTol}$ systems, respectively) and the $\mathrm{Pccb}$ products present no or low positive Gibbs energy stabilization (8.1, 4.9, and $-6.6 \mathrm{kcal} / \mathrm{mol}$ for $\mathrm{X}=\mathrm{OH}, \mathrm{OMe}$, and $\mathrm{NHpTol}$, respectively). Several reasons explain the high instability of TS2 $c c b$ and Pccb structures for $\mathrm{X}$ ligands with a second row element ( $\mathrm{N}$ or $\mathrm{O}$ ). First, as seen in Figure S1, the C6 atom of bipy shows a small positive charge at the intermediates preceding TS2 c cb, which means that it is a poor electrophile. Second, as it can be seen in Figures 8 and 9 , at TS2 $c \boldsymbol{c b}$ a six-membered non-planar metallacycle is starting to form and, as a consequence, the aromaticity in the attacked bipy ring becomes reduced, losing its planarity. When $\mathrm{X}$ ligand contains an $\mathrm{O}$ atom the $\mathrm{C} 2-\mathrm{C} 6$ bond is shorter, the aromatic ring is more distorted, that is, largest barriers correlate with larger aromaticity reductions. For the TS2 c c b and Pccb structures when $\mathrm{X}=\mathrm{OH}, \mathrm{OMe}$, and $\mathrm{NH} p \mathrm{Tol}$ the $\mathrm{Re}-\mathrm{X}$ bond is considerably longer than in the corresponding reactant complex (see Figure 9). The weakening of the bond with the metal may also contribute to the instability of these structures. When $\mathrm{X}=\mathrm{PPh}_{2}$, TS2 ccb presents a barrier of only $4.4 \mathrm{kcal} / \mathrm{mol}$, similar to that of TS2cco $(4.6 \mathrm{kcal} / \mathrm{mol})$ and much smaller than that of the other TS2ccb-type species. The loss of bipy aromaticity seems to be compensated by the formation of a loose six-membered metallacycle where the Re-P bond becomes stronger than in the initial reactant (with a shorter distance), which makes it particularly stable.

e) General discussion of the theoretical results and comparison with the experiment

In spite of the apparent similarity of $\left[\operatorname{Re}(\mathrm{X})(\mathrm{CO})_{3}(\right.$ bipy $\left.)\right](\mathrm{X}=\mathrm{OH}$, $\mathrm{OMe}, \mathrm{NH} p \mathrm{Tol}$, and $\mathrm{PPh}_{2}$ ) complexes, it has been experimentally found that the nature of the $X$ ligand determines the formation of different products in their reactivity towards activated alkynes, such as HMAD. The detailed analyses previously done for these reactions confirm experimental observations and shed some light on the reasons under this behavior. Actually, it is shown that the prevalence of one of the three possible products, Pcco (Pccoh, when present), Pins or Pccb, depends on a subtle balance between the kinetic barriers of the final step of their formation, since the initial nucleophilic approach of the $X$ ligand to the alkyne is common for routes leading to all of the products (see Figure 1), and their associated thermodynamic stability. These facts are not expected to change in the event that HMAD was computationally replaced by symmetric activated acetylenes like DMAD, since this substitution did not modify the kind of reaction product obtained experimentally. ${ }^{[49,51,52]}$ The presence of DMAD will lower the energy barrier of the initial nucleophilic approach to afford I1 as the acetylenic carbons (C1 and C2) for the isolated DMAD are less electronically populated $(\sim 0.12 e)$ than the analogous ones for HMAD and also the LUMO of
DMAD is lower in energy $(0.008 \mathrm{eV})$ than the analogous one of HMAD (see Table S17). By contrast, a slight increase in energy barriers for the formation of the different reaction products from $\mathbf{I 1}$ is expected, taking into account that $\mathrm{C} 2$ in $\mathbf{1 1}$ with DMAD is less electronically populated than that one with HMAD (see 11 for the NHpTol case in Figure S1 and Table S17). Nonetheless, this will not affect the selectivity of these reactive processes because the NBO charges of the three atoms attacked by $\mathrm{C} 2$ ( $R e, C_{C O}$, and $\left.C_{\text {bipy }}\right)$ are very similar to those found at $\mathbf{I 1}$ with HMAD (compare I1 in Figure S1 and Table S17).

For $\mathrm{X}=\mathrm{OH}$ and $\mathrm{NH} p \mathrm{Tol}$ the experimentally observed product is Pccoh ${ }^{[49,50]}$ The intramolecular addition to an equatorial $\mathrm{CO}$ ligand is an easy process for all four $\operatorname{Re}(\mathrm{I})$ complexes, to the point that it may not require surpassing a Gibbs energy barrier when $\mathrm{X}=\mathrm{OMe}$ and $\mathrm{NHpTOl}$ (TS2cco was not found for these ligands and instead it is the TS for 11 rearrangement (TS1_1') that ends up giving rise Pcco). However, only Pcco-type products are clearly more stable than the separate reactants for the $\mathrm{PPh}_{2}$ ligand and are always less stable than the corresponding $\mathbf{P} \boldsymbol{c c b}$ and Pins-type products. Only when $\mathrm{X}$ contains a nucleophilic atom bonded to a $\mathrm{H}$ atom $(\mathrm{X}=\mathrm{OH}$ and $\mathrm{NH}$ pTol), the addition to $\mathrm{CO}$ is followed by an accessible $\mathrm{H}$ transposition that yields the very stable species Pccoh as the preferred product in accordance with experimental findings. ${ }^{[49,50]}$ For the case of the $\left[\mathrm{Re}(\mathrm{NHpTol})(\mathrm{CO})_{3}(\right.$ bipy $\left.)\right]$ complex the PES has two different reaction channels from the beginning of the reaction. The channel leading to $\mathbf{P} c \boldsymbol{c b}$ is not competitive with that for the formation of Pccoh due to the large stabilization of this last product.

For $\mathrm{X}=\mathrm{OMe}$ the experimentally observed product is Pins. ${ }^{[4]}$ The ins route is the most kinetically unfavorable for $\mathrm{X}=\mathrm{PPh}_{2}$ due to the strong bond between Re and the third period element, phosphorous, that has to be broken at TS2ins; is kinetically unfavorable for $\mathrm{X}=\mathrm{OMe}$ and $\mathrm{NHpTol}$ due to fact that the structure previous to TS2ins, Pcco, needs to break two bonds (Re-O/N and $\mathrm{C} 2-\mathrm{CO}$ ) to yield the corresponding Pins; and becomes more favorable for $\mathrm{X}=\mathrm{OH}$ from I1' intermediate, where only the Re-O bond has to be broken. Thermodynamically, the ins route is favorable, since it yields very stable products with no charge separation for all complexes. For the particular case of the reaction of $\left[\operatorname{Re}(\mathrm{OMe})(\mathrm{CO})_{3}(\right.$ bipy $\left.)\right]$ with $\mathrm{HMAD}$, the lower Gibbs energy barrier of TS2ins compared to its potential competitor TS2ccb determines, according to experimental evidences ${ }^{[47]}$ the formation of Pins as the main reaction product (besides the large thermodynamic stability of the insertion product Pins).

Eventually, for the complex with the $\mathrm{PPh}_{2}$ ligand, intermediate I1' exists and is the separation point for the independent routes leading to each of the products (Pcco, Pins or Pccb) via the corresponding TS (TS2cco, TS2ins or TS2ccb). Compared to $X$ $=\mathrm{OH}, \mathrm{OMe}, \mathrm{NH} p \mathrm{Tol}$, the presence of a larger nucleophilic atom at the $X$ ligand like phosphorous relieves the ring strain of the four, five, and six-member metallacycles at TS2ins, TS2cco, and TS2ccb, respectively. This causes an important stabilization of TS2cco and TS2ccb, and to a much lesser extent TS2ins due to the strength of the Re-P bond. As a result, the addition routes to $\mathrm{CO}$ and bipy, kinetically similar, are much more 
favorable than the insertion one. The largest stability of the Pccb product determines a preference for the formation of Pccb, as experimentally observed. ${ }^{[51,52]}$ Except for the complex with $\mathrm{X}=$ $\mathrm{PPh}_{2}$, the route for the coupling with the bipy ligand $\left(C-C_{\text {bipy }}\right)$ is quite unfavorable both kinetically and thermodynamically.

As just said, the formation of the products experimentally detected, Pccoh ( $C-C_{C O H}$ coupling product) for $\mathrm{OH}$ and $\mathrm{NH} p \mathrm{Tol}$, Pins (insertion product) for $\mathrm{OMe}$, and $\mathrm{Pccb}\left(\mathrm{C}-\mathrm{C}_{\text {bipy }}\right.$ coupling product) for $\mathrm{PPh}_{2}$, could be rationalized in this work and some reactivity guidelines seem to be emerging. The understanding of the independent or combined effects of the heteroatoms and their substituents at the $X$ ligand on this reactivity will benefit from a systematic study involving complexes not yet experimentally tested that is under way in our laboratory.

\section{Conclusions}

A comparative mechanistic study on the reactions of $\left[\operatorname{Re}(\mathrm{X})(\mathrm{CO})_{3}(\right.$ bipy $\left.)\right]\left(\mathrm{X}=\mathrm{OH}, \mathrm{OMe}, \mathrm{NHpTol}, \mathrm{PPh}_{2}\right.$; bipy $=2,2^{\prime}-$ bipyridine) towards methyl propiolate (HMAD) was carried out at the CPCM-DLPNO-CCSD(T)/def2-TZVPP//PCM-B3LYP/6$31+G(d, p)-L A N L 2 D Z$ level of theory to understand the effect of ligand $X$ on the selectivity of the reaction. Three different reaction patterns were found having in common the initial nucleophilic attack of the $X$ ligand on the terminal acetylenic carbon of HMAD. First, for $\mathrm{OH}$ and $\mathrm{PPh}_{2}$ initial reactive approaches lead to the formation of a zwitterionic intermediate that subsequently becomes an isomeric zwitterion. This species is the splitting point for the reaction paths leading to three possible products: the addition of the X-bonded acetylene to one of the $\mathrm{CO}$ ligands in trans disposition to the bipy one $\left(C-C_{C O}\right.$ coupling product), the $R e$ atom in an insertion process (ins product) or the bipy ligand ( $C$ - $C_{\text {bipy }}$ coupling product). Second, for OMe, the zwitterion formed at the first step evolves directly to the $C-C_{C O}$ coupling species, which is the splitting structure towards the ins and $C$ - $C_{\text {bipy }}$ products. Third, for $\mathrm{NHpTol}$ two approaching orientations of the reactants render separate routes, one leading to the $C-C_{\text {bipy }}$ product and the other to the $C-C_{C O}$ product to which, the ins product is linked. In addition, for $X$ ligands containing a hydrogen atom bonded to the nucleophilic atom, $\mathrm{OH}$ and $\mathrm{NHpTol}$, we have found an intermolecular mechanism for the evolution of $C-C_{C O}$ species evolves to a more stable one, $C-C_{C O H}$ product, where that $\mathrm{H}$ atom has shifted to the oxygen atom of the attacked carbonyl ligand. According to our computations, the ester group in HMAD plays a two-fold role by activating the alkyne for the initial nucleophilic addition and by assisting an intermolecular hydrogen migration from $C-C_{C O}$ to $C$ $\mathrm{C}_{\mathrm{COH}}$ species in these complexes.

The reaction rate of the reactive processes investigated is determined by the initial nucleophilic attack step. Since this step is common for all the reactions, the preferred product depends on the kinetics and/or thermodynamics ascribed to the last part of the corresponding reaction profile. The formation of $C-C_{C O}$ species is kinetically more favored than that of $C$ - $C_{\text {bipy }}$ and ins ones, except for $\mathrm{X}=\mathrm{PPh}_{2}$ where the energy barriers for the generation of $C-C_{C O}$ and $C$ - $C_{\text {bipy }}$ species compete with each other. By contrast, thermodynamics always favors the formation of ins, $C$ - $C_{\text {bipy }}$ or, when present, $C-C_{C O H}$ species over the $C-C_{C O}$ one. Specifically, when $\mathrm{X}=\mathrm{OH}$ and $\mathrm{NHpTol}$, an easy intramolecular attack of the HMAD that was just linked to a highly electrophilic $\mathrm{CO}$ equatorial ligand is followed by the formation of the very stable $\mathrm{C}-\mathrm{C}_{\mathrm{COH}}$ products. When $\mathrm{X}=\mathrm{OMe}$, the ins product forms thanks to the smaller barrier and the larger stability of the ins route compared to that of its potential competitor, the $C$ - $C_{\text {bipy }}$ product. Finally, when $\mathrm{X}=\mathrm{PPh}_{2}$ the ins route becomes restricted and, therefore the $C-C_{\text {bipy }}$ coupling wins over the $C-C_{C O}$ one, but only for the largest stability of the $C-C_{\text {bipy }}$ product. Based on this, the products experimentally detected, $C-C_{\mathrm{COH}}$ for $\mathrm{OH}$ and $\mathrm{NHpTol}$, ins for $\mathrm{OMe}$, and $C-C_{\text {bipy }}$ for $\mathrm{PPh}_{2}$, could be rationalized and some general reactivity trends have been unveiled. Therefore, the information collected can help design new rhenium carbonyl complexes and other related systems with improved technological, biomedical or chemical synthesis applications.

\section{Acknowledgments}

The authors thank the governments of Spain (grants CTQ201570231-P and PG2018-100013-B-I00) and Principado de Asturias (grant FC-15-GRUPIN14-103) for financial support. We also acknowledge computing resources from the Fundación Computación y Tecnologías Avanzadas de Extremadura (COMPUTAEX) (JD). We are grateful to both D. Suárez and J. Pérez, from the University of Oviedo (Spain), and R. MeraAdasme, from the University of Santiago de Chile (USACH), for useful suggestions to the manuscript and calculations.

Keywords: rhenium complexes $\cdot$ nucleophilic addition $•$ ligand effects $\cdot$ reaction mechanisms $\cdot$ computational chemistry

[1] J. Hawecker, J. M. Lehn, R. Ziessel, J. Chem. Soc., Chem. Commun. 1983, 536-538.

[2] J. Hawecker, J. M. Lehn, R. Ziessel, J. Chem. Soc., Chem. Commun. 1984, 328-330.

[3] B. P. Sullivan, C. M. Bolinger, D. Conrad, W. J. Vining, T. J. Meyer, J. Chem. Soc., Chem. Commun. 1985, 1414-1416.

[4] J. Hawecker, J. M. Lehn, R. Ziessel, Helv. Chim. Acta 1986, 69, 19902012.

[5] Y. Hayashi, S. Kita, B. S. Brunschwig, E. Fujita, J. Am. Chem. Soc. 2003, 125, 11976-11987.

[6] P. Kurz, B. Probst, B. Spingler, R. Alberto, Eur. J. Inorg. Chem. 2006, 2966-2974.

[7] H. Takeda, K. Koike, H. Inoue, O. Ishitani, J. Am. Chem. Soc. 2008, 130, 2023-2031.

[8] B. Probst, A. Rodenberg, M. Guttentag, P. Hamm, R. Alberto, Inorg. Chem. 2010, 49, 6453-6460.

[9] J. M. Smieja, C. P. Kubiak, Inorg. Chem. 2010, 49, 9283-9289.

[10] H. Takeda, O. Ishitani, Coord. Chem. Rev. 2010, 254, 346-354.

[11] B. Probst, M. Guttentag, A. Rodenberg, P. Hamm, R. Alberto, Inorg. Chem. 2011, 50, 3404-3412.

[12] K. A. Grice, C. P. Kubiak, A. Michele, E. van Rudi, Adv. Inorg. Chem. 2014, 66, 163-188. 
[13] J. J. Teesdale, A. J. Pistner, G. P. A. Yap, Y. Z. Ma, D. A. Lutterman, J. Rosenthal, Catal. Today 2014, 225, 149-157.

[14] C. Matlachowski, B. Braun, S. Tschierlei, M. Schwalbe, Inorg. Chem. 2015, 54, 10351-10360.

[15] T. W. Schneider, M. Z. Ertem, J. T. Muckerman, A. M. Angeles-Boza, ACS Catal. 2016, 6, 5473-5481.

[16] C. Kefalidi, E. Koutsouri, L. Marchiò, A. Zarkadoulas, S. Efstathiadou, C. A. Mitsopoulou, Polyhedron 2016, 110, 157-164

[17] E. Koutsouri, C. A. Mitsopoulou, Open Chem. 2016, 14, 393-403.

[18] M. L. Clark, P. L. Cheung, M. Lessio, E. A. Carter, C. P. Kubiak, ACS Catal. 2018, 8, 2021-2019.

[19] D. B. MacQueen, K. S. Schanze, J. Am. Chem. Soc. 1991, 113, 61086110.

[20] K. S. Schanze, D. B. MacQueen, T. A. Perkins, L. A. Cabana, Coord. Chem. Rev. 1993, 122, 63-89.

[21] S. S. Sun, A. J. Lees, J. Am. Chem. Soc. 2000, 122, 8956-8967.

[22] M. Bakir, Acta Crystallogr., Sect. C: Struct. Chem., 2001, 57, 13711373.

[23] A. S. Polo, M. K. Itokazu, K. M. Frin, A. O. de T. Patrocínio, N. Y. M. Iha, Coord. Chem. Rev. 2006, 250, 1669-1680.

[24] D. Pelleteret, N. C. Fletcher, A. P. Doherty, Inorg. Chem. 2007, 46, 4386-4388.

[25] M. C. L. Yeung, V. W. W. Yam, Chem. Soc. Rev. 2015, 44, 4192-4202.

[26] A. Zarkadoulas, E. Koutsouri, C. Kefalidi, C. A. Mitsopoulou, Coord. Chem. Rev. 2015, 304-305, 55-72.

[27] (a) N. J. Lundin, A. G. Blackman, K. C. Gordon, D. L. Officer, Angew. Chem. Int. Ed., 2006, 45, 2582-2584. (b) G. W. Zhaoa, J. H. Zhaoa, Y X. Hua, D. Y. Zhangb, X. Lia, Synth. Met. 2016, 212, 131-141.

[28] G. Gasser, I. Ott, N. Metzler-Nolte, J. Med. Chem. 2011, 54, 3-25

[29] A. Leonidova, V. Pierroz, L. A. Adams, N. Barlow, S. Ferrari, B. Graham, G. Gasser, ACS Med. Chem. Lett. 2014, 5, 809-814.

[30] A. Leonidova, G. Gasser, ACS Chem. Biol. 2014, 9, 2180-2193.

[31] M. Kaplanis, G. Stamatakis, V. D. Papakonstantinou, M. ParavatouPetsotas, C. A. Demopoulos, C. A. Mitsopoulou, J. Inorg. Biochem. 2014, 135, 1-9.

[32] R. R. Ye, C. P. Tan, M. H. Chen, L. Hao, L. N. Ji, Z. W. Mao, Chem. Eur. J. 2016, 22, 7800-7809.

[33] K. M. Knopf, B. L. Murphy, S. N. MacMillan, J. M. Baskin, M. P. Barr, E. Boros, J. J. Wilson, J. Am. Chem. Soc. 2017, 139, 14302-14314.

[34] S. C. Marker, S. N. MacMillan, W. R. Zipfel, Z. Li, P. C. Ford, J. J. Wilson, Inorg. Chem. 2018, 57, 1311-1331.

[35] M. Salmain, M. Gunn, A. Gorfti, S. Top, G. Jaouen, Bioconjugate Chem. 1993, 4, 425-433.

[36] W. B. Connick, A. J. DiBilio, M. G. Hill, J. R. Winkler, H. B. Gray, Inorg. Chim. Acta 1995, 240, 169-173.

[37] T. A. Oriskovich, P. S. White, H. H. Thorp, Inorg. Chem. 1995, 34, 1629-1631.

[38] K. K.-W. Lo, W.-K. Hui, C.-K. Chung, K. H.-K. Tsang, T. K.-W. Lee, C.K. Li, J. S.-Y. Lau, D. C.-M. Ng, Coord. Chem. Rev. 2006, 250, 1724 1736 .

[39] C. Beck, J. Brewer, J. Lee, D. McGraw, B. A. DeGraff, J. N. Demas, Coord. Chem. Rev. 2007, 251, 546-553.

[40] K. K.-W. Lo, M.-W. Louie, K.-S. Sze, J. S.-Y. Lau, Inorg. Chem. 2008, 47, 602-611.

[41] V. Fernández-Moreira, F. L. Thorp-Greenwood, M. P. Coogan, Chem. Commun. 2010, 46, 186-202.

[42] K. K.-W. Lo, M.-W. Louie, K. Y. Zhang, Coord. Chem. Rev. 2010, 254 , 2603-2622.

[43] K. K.-W. Lo, K. Y. Zhang, S. P.-Y. Li, Eur. J. Inorg. Chem. 2011, 35513568.

[44] R. Balasingham, M. P. Coogan, F. L. Thorp-Greenwood, Dalton Trans. 2011, 40, 11663-11674.

[45] K. K.-W. Lo, A. W.-T. Choi, W. H.-T. Law, Dalton Trans. 2012, 41, 6021-6047.
[46] J. Skiba, T. Bernas, D. Trzybinski, K. Wozniak, G. Ferraro, D. Marasco, A. Merlino, M. Z. Shafikov, R. Czerwieniec, K. Kowalski, Molecules 2017, 22, 809-820.

[47] E. Hevia, J. Pérez, L. Riera, V. Riera, Organometallics 2002, 21, 1750 1752.

[48] E. Hevia, J. Pérez, L. Riera, V. Riera, I. del Río, S. García-Granda, D. Miguel, Chem. Eur. J. 2002, 8, 4510-4521.

[49] E. Hevia, J. Pérez, V. Riera, D. Miguel, Organometallics 2003, 22, 257263.

[50] L. Cuesta, D. C. Gerbino, E. Hevia, D. Morales, M. E. NavarroClemente, J. Pérez, L. Riera, V. Riera, D. Miguel, I. del Río, S. GarcíaGranda, Chem. Eur. J. 2004, 10, 1765-1777.

[51] L. Cuesta, E. Hevia, D. Morales, J. Pérez, V. Riera, E. Rodríguez, D. Miguel, Chem. Commun. 2005, 116-117.

[52] L. Cuesta, E. Hevia, D. Morales, J. Pérez, V. Riera, M. Seitz, D. Miguel, Organometallics 2005, 24, 1772-1775.

[53] R. Arévalo, M. Espinal-Viguri, M. A. Huertos, J. Pérez, L. Riera, Adv. Organomet. Chem. 2016, 65, 47-114.

[54] F. Villafañe, Coord. Chem. Rev. 2017, 339, 128-137.

[55] M. T. Ashby, J. H. Enemark, Organometallics 1987, 6, 1323-1327.

[56] H. Adams, N. A. Bailey, A. N. Day, M. J. Morris, M. M. Harrison, J. Organomet. Chem. 1991, 407, 247-258.

[57] A. L. Serrano, M. A. Casado, M. A. Ciriano, B. de Bruin, J. A. López, C. Tejel, Inorg. Chem. 2016, 55, 828-839.

[58] A. Antiñolo, S. García-Yuste, I. Lopez-Solera, A. Otero, J.C. PérezFlores, R. Reguillo-Carmona, E. Villaseñor, E. Santos, E. Zuidema, C. Bo, Dalton Trans. 2010, 39, 1962-1971.

[59] C. Huang, H. Liu, J. Zhang, Z. Duan, F. Mathey, Eur. J. Inorg. Chem. 2010, 5498-5502.

[60] D. A. M. Kurtz, K. R. Brereton, K. P. Ruoff, H. M. Tang, G. A. N. Felton, A. J. M. Miller, J. L. Dempsey, Inorg. Chem. 2018, 57, 5389-5399.

[61] D. Álvarez, R. Mera-Adasme, L. Riera, G. I. Cárdenas-Jirón, J. Pérez, J. Díaz, M. I. Menéndez, R. López, Inorg. Chem. 2017, 56, 6652-6661.

[62] (a) C. Gonzalez, H. B. Schlegel, J. Chem. Phys. 1989, 90, 2154-2161. (b) C. Gonzalez, H. B. Schlegel, J. Phys. Chem. 1990, 94, 5523-5527.

[63] (a) C. Riplinger, F. Neese, J. Chem. Phys. 2013, 138, 034106-18. (b) C Riplinger, B. Sandhoefer, A. Hansen, F. Neese, J. Chem. Phys. 2013, 139, 134101-13.

[64] (a) F. Weigend, R. Ahlrichs, Phys. Chem. Chem. Phys. 2005, 7, 32973305. (b) D. Andrae, U. Haeussermann, M. Dolg, H. Stoll, H. Preuss, Theor. Chim. Acta 1990, 77, 123-141.

[65] (a) V. Barone, M. Cossi, J. Phys. Chem. A 1998, 102, 1995-2001. (b) J. L. Pascual-Ahuir, E. Silla, J. Comput. Chem. 1990, 11, 1047-1060. (c) J. L. Pascual-Ahuir, E. Silla, I. Tuñón, J. Comput. Chem. 1991, 12, 10771088. (d) J. L. Pascual-Ahuir, E. Silla, I. Tunón, J. Comput. Chem. 1994, 15, 1127-1138. (e) T. N. Truong, E. V. Stefanovich, Chem. Phys. Lett. 1995, 240, 253-260.

[66] T. J. Lee, P. R. Taylor, Int. J. Quantum Chem. 1989, 36, 199-207.

[67] D. G. Liakos, F. Neese, J. Chem. Theory Comput. 2015, 11, 4054-4063.

[68] D. A. McQuarrie, Statistical Mechanics, Harper and Row: New York, 1976.

[69] R. F. Ribeiro, A. V. Marenich, C. J. Cramer, D. G. Truhlar, J. Phys. Chem. B 2011, 115, 14556-14562.

[70] (a) E. D. Glendening, A. E. Reed, J. E. Carpenter, F. Weinhold, NBO Version 3.1.; University of Wisconsin: Madison, WI, 2012. (b) F. Weinhold, C.R. Landis, Valency and Bonding: A Natural Bond Orbital Donor-Acceptor Perspective; Cambridge University Press: Cambridge, 2005

[71] M. J. Frisch, G. W. Trucks, H. B. Schlegel, G. E. Scuseria, M. A. Robb, J. R. Cheeseman, G. Scalmani, V. Barone, B. Mennucci, G. A Petersson, H. Nakatsuji, M. Caricato, X. Li, H. P. Hratchian, A. F. Izmaylov, J. Bloino, G. Zheng, J. L. Sonnenberg, M. Hada, M. Ehara, K. Toyota, R. Fukuda, J. Hasegawa, M. Ishida, T. Nakajima, Y. Honda, O. Kitao, H. Nakai, T. Vreven, J. A. Jr Montgomery, J. E. Peralta, F. Ogliaro, M. Bearpark, J. J. Heyd, E. Brothers, K. N. Kudin, V. N. 
Staroverov, R. Kobayashi, J. Normand, K. Raghavachari, A. Rendell, J. C. Burant, S. S. lyengar, J. Tomasi, M. Cossi, N. Rega, J. M. Millam, M. Klene, J. E. Knox, J. B. Cross, V. Bakken, C. Adamo, J. Jaramillo, R. Gomperts, R. E. Stratmann, O. Yazyev, A. J. Austin, R. Cammi, C. Pomelli, J. W. Ochterski, R. L. Martin, K. Morokuma, V. G. Zakrzewski, G. A. Voth, P. Salvador, J. J. Dannenberg, S. Dapprich, A. D. Daniels, O. Farkas, J. B. Foresman, J. V. Ortiz, J. Cioslowski, D. J. Fox, Gaussian 09, Revision A.1, Gaussian, Inc., Wallingford CT, 2009.

[72] (a) X. Fradera, M. A. Austen, R. F. W. Bader, J. Phys. Chem. A 1999, 103, 304-314. (b) X. Fradera, J. Poater, S. Simon, M. Durán, M. Solá, Theor. Chem. Acc. 2002, 108, 214-224.

[73] T. A. Keith, AIMAll program, Version 10.12.11, 2010.
[74] (a) R. F. W. Bader, Atoms in Molecules. A Quantum Theory; University Press: Oxford, 1990. (b) R. F. W. Bader, Chem. Rev. 1991, 91, 893928.

[75] F. Neese, Software Update: The ORCA Program System, Version 4.0.1, WIREs Comput. Mol. Sci. 2018, 8: e1327. DOI: 10.1002/wcms.1327. 


\section{Entry for the Table of Contents}

\section{FULL PAPER}

Computations reveal that the YR ligand determines both the reaction pattern and the obtained product in the reaction between $\left[\operatorname{Re}(\mathrm{YR})(\mathrm{CO})_{3}(\right.$ bipy $\left.)\right]$ complexes and activated alkynes. Since all patterns start with the same nucleophilic addition, the experimental selectivity is dictated by the kinetics and/or thermodynamics of the last stage of the reaction.

\section{Coordination Chemistry}

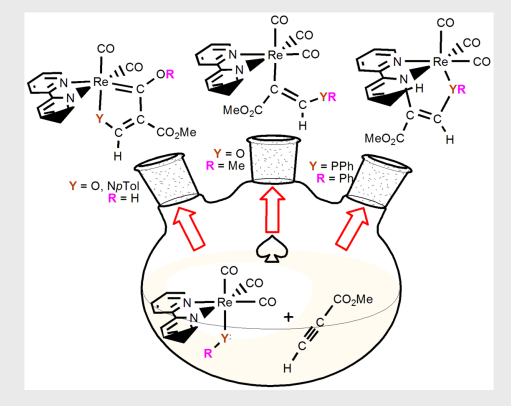

Daniel Álvarez, Jesús Díaz, M. Isabel Menéndez, Ramón López*

Page No. - Page No.

Addition of Re-Bonded Nucleophilic Ligands to Activated Alkynes: A

Theoretical Rationalization 